\title{
Plant Extracts as Green Corrosion Inhibitors for Different Metal Surfaces and Corrosive Media: A Review
}

\author{
Alan Miralrio ${ }^{1, *(D)}$ and Araceli Espinoza Vázquez ${ }^{2, *}$ \\ 1 Tecnologico de Monterrey, Escuela de Ingeniería y Ciencias, Ave. Eugenio Garza Sada 2501, \\ Monterrey 64849, N.L., Mexico \\ 2 Instituto de Investigaciones en Materiales, Universidad Nacional Autónoma de México, \\ Circuito Exterior S/N, Cd. Universitaria, Coyoacán, Mexico City 04360, Mexico \\ * Correspondence: miralrio@tec.mx (A.M.); arasv_21@yahoo.com.mx (A.E.V.)
}

Received: 3 June 2020; Accepted: 22 July 2020; Published: 6 August 2020

\begin{abstract}
Natural extracts have been widely used to protect metal materials from corrosion. The efficiency of these extracts as corrosion inhibitors is commonly evaluated through electrochemical tests, which include techniques such as potentiodynamic polarization, electrochemical impedance spectroscopy, and weight loss measurement. The inhibition efficiency of different extract concentrations is a valuable indicator to obtain a clear outlook to choose an extract for a particular purpose. A complementary vision of the effectiveness of green extracts to inhibit the corrosion of metals is obtained by means of surface characterizations; atomic force microscopy, scanning electron microscopy, and X-ray photoelectron spectroscopy analysis are experimental techniques widely used for this purpose. Moreover, theoretical studies are usually addressed to elucidate the nature of the corrosion inhibitor-metal surface interactions. In addition, calculations have been employed to predict how other organic substances behave on metal surfaces and to provide experimental work with fresh proposals. This work reports a broad overview of the current state of the art research on the study of new extracts as corrosion inhibitors on metal surfaces in corrosive media. Most constituents obtained from plant extracts are adsorbed on the metal, following the Langmuir adsorption model. Electron-rich regions and heteroatoms have been found to be responsible for chemisorption on the metal surface, whereas physisorption is due to the polar regions of the inhibitor molecules. The plant extracts compiled in this work obtained corrosion inhibition efficiencies above 60\%, most of them around 80-90\%. The effect of concentration, extraction solvent, temperature, and immersion time were studied as well. Additional studies regarding plant extracts as corrosion inhibitors on metals are needed to produce solutions for industrial purposes.
\end{abstract}

Keywords: steel; copper; aluminum; green corrosion inhibition; plant extracts

\section{Introduction}

Metals are widely used in human activities due to their excellent mechanical and electrical properties [1-4]. In order to preserve the desired state of these metals, their preventive maintenance is a priority. Corrosion is probably the most common undesired phenomenon that leads metals to become weaker $[5,6]$. This natural process originates from the electrochemical interaction of metals with the corrosive environment. Sulfides, oxides, and others are generated through reactions between the metal surface and the corrosive medium [6-9].

Among metals, mild steel is the most widely used in the oil, food, energy, chemical, and construction industries due to its different applications, most of which are based on its excellent mechanical properties. This metal shows high mechanical resistance, durability, and toughness, among others, 
which makes it a highly available material and at a relatively low cost. Consequently, solutions to problems related to the degradation by the corrosion of steel, mostly mild steel, is a high-priority topic. To a lesser extent, copper and aluminum alloys are studied as well. The high cost associated with corrosion, due to the replacement of rusted metals, can be reduced by using corrosion inhibitors [10].

\subsection{Corrosion Inhibition Fundamentals}

Constituting the archetypal source for mineralization and corrosion phenomena, seawater is an example of a common corrosive medium, containing an abundance of chloride ions, including massive waterbodies around the world: oceans, seas, and salt lakes [11]. On the other hand, hydrochloric acid $(\mathrm{HCl})$ is frequently used both in decalcification processes and to produce corrosion under controlled conditions [1]. Several authors employ $1 \mathrm{M} \mathrm{HCl}$ solutions, making it the most prominent corrosion medium to study corrosion since it is extremely aggressive and can be used to obtain an idea regarding corrosion on a certain metal [12-16]. Other solutions recurrently used as corrosive media are 3.5\% $\mathrm{NaCl}$ [17-22], $0.1 \mathrm{M} \mathrm{HCl}$ [23], and $0.1 \mathrm{M} \mathrm{NaOH}$ [24-26]. To a lesser extent, $1 \mathrm{M} \mathrm{H}_{3} \mathrm{PO}_{4}$ and $0.5 \mathrm{M} \mathrm{H}_{2} \mathrm{SO}_{4}$ are used as test solutions as well [27-31]

Corrosion inhibitors are substances that are added in small amounts on metal surfaces or are added to the corrosive medium, reducing the tendency to be affected by corrosion. The use of common corrosion inhibitors is sometimes limited, since these are based on dangerous substances for human health, such as chromium-based treatments [32]. Recent approaches take advantage of organic compounds that can be obtained from expired pharmaceutic drugs, mushroom extracts, and even plant extracts [33-37]. There is a variety of green organic compounds that function as corrosion inhibitors that show excellent properties in protecting metal surfaces, for example, derivatives of chitosan [38], phenylmethanimine [39], imidazoline [40], and ionic liquid [41]. In consequence, these compounds replace the traditional toxic corrosion inhibitors. Highly efficient corrosion inhibitors have been achieved by means of these substances, providing new recycling and reusing routes for drugs as well as corrosion inhibitors obtained from sustainable, ecological, and environmentally friendly sources, with plant extracts being a prominent group [25,42]. These extracts constitute another option of great interest, since they offer the possibility of a first approach to determine the class of natural compounds that help inhibit the corrosion process. The advantage is that making an extract from any plant is regarded as an uncomplicated task, thus allowing more efficiency at both extraction and use of these substances for experimentation.

An extract is a solution composed by the active principles of a plant or its parts (Figure 1) and a certain medium acting as solvent. The extraction yields depend on the polarity of the solvent used, in the techniques or methods (Soxhlet and maceration), among others. Active principles contained in the extract give the properties for a particular purpose. Thus, a given plant, in terms of its active principles and concentrations, can be associated with some benefits. These extracts are mostly known by their antioxidant, anti-inflammatory, antiviral, or antimicrobial effects. In addition, their corrosion inhibitor properties can be considered as synergic effects. Extracts are commonly obtained from the whole plant or the parts containing higher concentrations of active principles, named phytochemicals $[43,44]$. According to the literature, extracts of plants, fruits, seeds, flowers, and leaves contain active compounds that are promising for corrosion inhibition in aggressive media. Moreover, these compounds become cheap, widely available, and renewable corrosion inhibitor alternatives [45-49]. Thus, a review on the novel plant extracts that have been proven to be highly efficient corrosion inhibitors is necessary. This manuscript provides a wide landscape of the recently reported plant extracts as corrosion inhibitors in steel as well as aluminum and copper alloys. Basic aspects of the extraction methods, characterization techniques, theoretical modelling, and adsorption mechanisms are also discussed. 


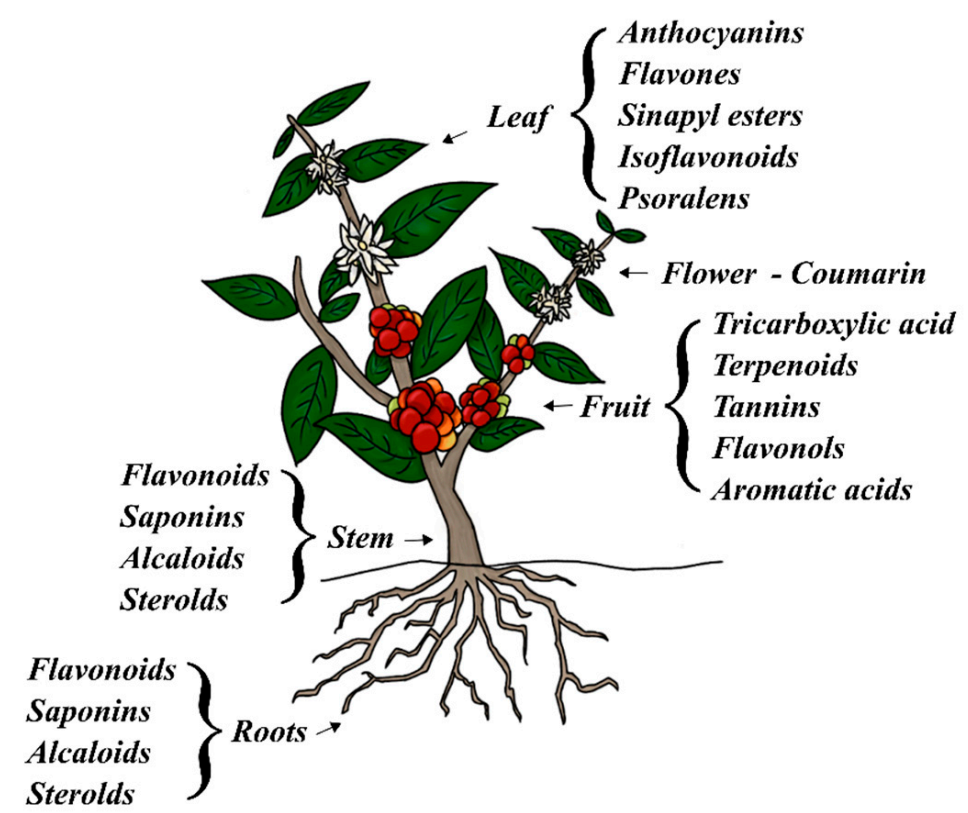

Figure 1. Basic parts of a plant and their common active compounds.

\subsection{Extraction Methods}

The vast variety of extraction methods used nowadays exceed by far the purpose of this review. However, a brief review on extraction methods is included below. The first step is to choose the part of the plant with the major concentration of active compounds of interest. All plant parts-leaves, flowers, seeds, fruits, roots, and stems-are used to obtain the extracts. In brief, extraction methods are based on heating, cooling, and separating the active compounds in the presence of the solvent.

Secondly, traditional extraction methods can be summarized in maceration, infusion decoction, digestion, and percolation (Figure 2) [50]. In general, the form of the extract method is applicable on the basis of what is desired to be obtained. In maceration, crushed, smashed, or cut materials, sometimes previously dried, are immersed in the extraction solvent for periods of at least 3 days in constant agitation (Figure 2a). The diffusion of the solvent in the targeted material solubilizes the active compounds, leading to their possible extraction. The solids suspended in the resulting mixture can be separated by filtering. For this method, the advantage is that all the essence is extracted without altering it, and the active ingredients are easily soluble. The infusion method yields the extract by means of maceration for a short period of time in the presence of boiling water. Thus, the most soluble constituents are solubilized, passing to the extract. Similarly, in the decoction process, the crude drug is boiled in a specific volume of water for a defined time (Figure 2c). The digestion method proposes the maceration of the raw materials in the presence of a slightly warm solvent, improving the solubility of the extraction solvent and preserving the active compounds from decomposition (Figure 2). Percolation is a filtration method, at room temperature, in which the moistened raw material is placed in a conical vessel, the percolator, with an adjustable closure (Figure $2 b$ ). Then, the percolator must be filled with solvent and covered up, obtaining the extract drop by drop [51]. The advantages of percolation lie in the high performance of active substances, in the short time required for their manufacture and the economy of the materials used.

More sophisticated methods are hot continuous extraction and ultrasound extraction or sonication [52]. The first one uses the Soxhlet apparatus, formed by a glass body with boiling flask, a siphon arm, thimble, extraction chamber, and condenser (Figure 2d) [52]. In brief, the boiling flask containing the solvent is heated and the vapor produced is condensed. The resultant liquid falls into the thimble containing the raw material, and the extract fills the extraction chamber up in order to put into function the siphon arm to return the liquid into the boiling flask. The reflux process must be stopped up to obtain the degree of extraction desired. Finally, sonication is a technique that uses 
high energy ultrasounds to improve permeability of cell walls, producing cavitation to disrupt cellular membranes (Figure 2e) [53]. Consequently, sonication breaks the cells, releasing their content for further extraction. Liquids obtained by the methods introduced above are then clarified by filtration or decantation.
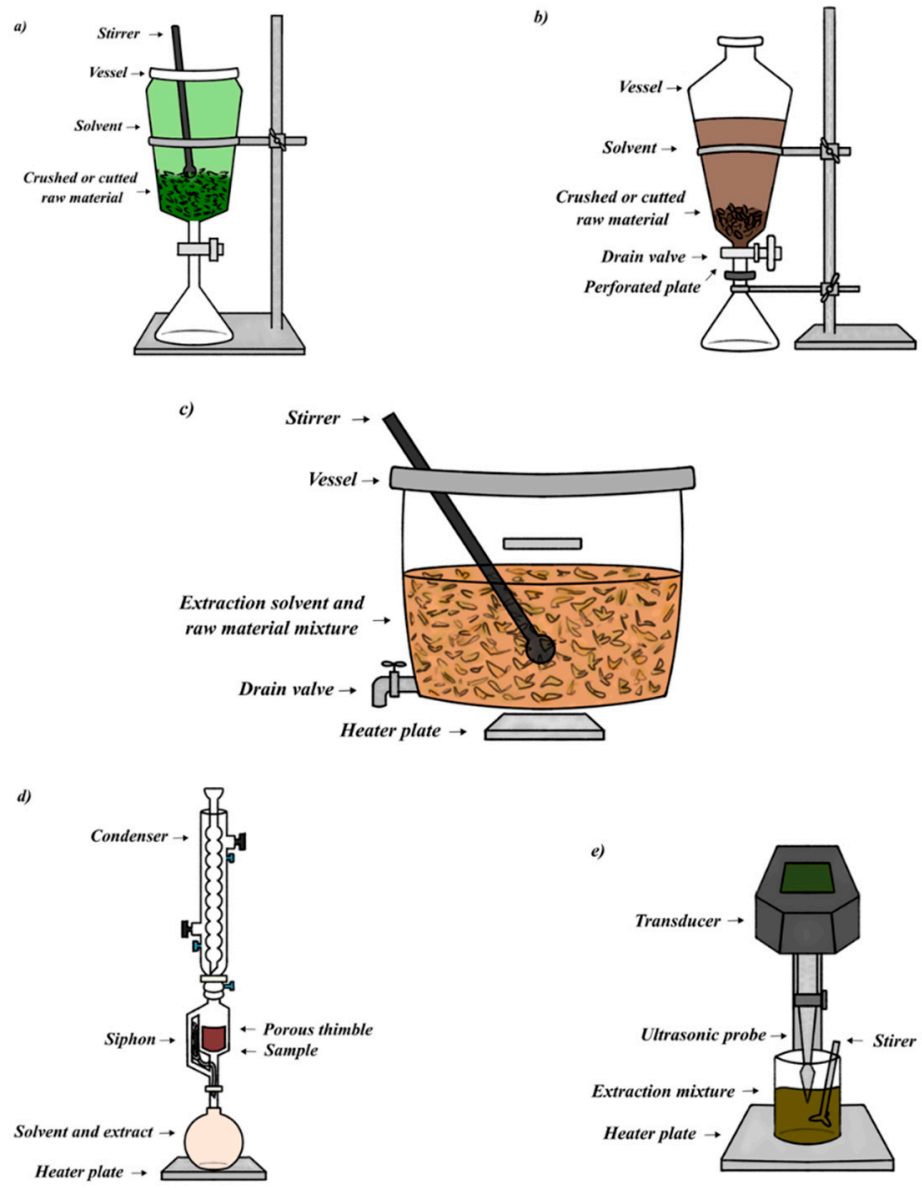

Figure 2. Diagrams of common extraction methods: (a) maceration, (b) percolation, (c) decoction, (d) Soxhlet, and (e) sonication.

The solvent has a key role in the extraction methods, since it is responsible for solubilizing the active compounds when it diffuses through plant tissues, making their extraction possible. Extraction solvents have shown to affect the physical, chemical, and antioxidant properties of the extracts obtained, as the concentration of flavonoids, saponins, phenolic compounds, and others present in plant extracts vary according to the extraction solvent [54-56]. Consequently, various solvents have been used to obtain the desired concentration of active compounds from plant extracts. Then, the efficient extraction of active compounds depends on the solvent used, among which the most common are water, methanol, ethyl acetate, dichloromethane, and hexane [54-56]. Water could be the most convenient extraction solvent, since it is highly available, non-toxic, non-flammable, and inexpensive [57-59]. Not all plant extracts can be obtained as aqueous extracts, giving the chance to test other solvents. Thus, solvents are selective and, in order to obtain the optimal yield, several options must be tested.

Other important parameters for the extraction process are drying and extraction temperatures. The first one marks the temperature to get the plant dry, although room temperature is commonly used since plants are usually dried in the shade. The use of dried plants has benefits, being suitable for long storage and with reduced weight. In contrast, the drying process has been shown to affect the stability of bioactive compounds and the antioxidant capacity [54,60]. Fresh plants can be used instead of dried ones, although their use could produce some drawbacks as well. Fresh plants could be subject to degradation by solar radiation, and some of their constituents could be easily evaporated 
or oxidized. However, in some cases, phytochemicals could be extracted in higher concentrations from fresh samples instead of dried ones [61-63]. The extraction temperature is another important parameter since a high temperature promotes the decomposition of phytochemicals and a lower one reduces the solubility of active compounds and hinders its extraction. To achieve the optimal concentration of phytochemicals requires the correct choice of extraction temperatures, extraction cost, solvent, and others [64].

\subsection{Characterization Techniques}

A proper characterization of the extracts proposed as corrosion inhibitors is needed; consequently, several experimental techniques are available for this purpose. Cyclic potentiodynamic polarization (PP) is used for evaluating the susceptibility of a metal to localized corrosion such as pitting and crevice [65]. Polarization tests, such as PP, are based on the evaluation and analysis of the current produced by a variable potential in a working electrode [65]. Another recurrently used technique to study anti-corrosion performance, in considerable short testing times, is electrochemical impedance spectroscopy (EIS) [66]. This technique is used to determine the impedance of a system in terms of the frequency of a variable potential. The analysis of EIS results relies on models with equivalent electrical circuits, with the most recurrent graphical representations of its results being Nyquist plots [67]. EIS shows more information, for example, mechanism and different resistance of the system. Linear polarization resistance (LPR) is a technique used to obtain the corrosion rate by determining the relationship between electrochemical potential and generated currents on charged electrodes [68]. Less sophisticated and time-consuming is the weight loss method (WL), since this technique is based on the mass lost by corrosion, which is directly monitored to get the corrosion rate. Some properties measured in the presence and absence of the substance used as corrosion inhibitor, such as corrosion current density obtained by PP, can be used to obtain the inhibition efficiency [66].

Surface characterization is commonly addressed by means of spectroscopy and microscopy techniques. Scanning electron microscope (SEM) provides a clear comparison between the metal surface with and without a corrosion inhibitor, as well as other morphological information $[69,70]$. Similarly, the atomic force microscope (AFM) obtains information regarding the shape of the metal surface for comparison purposes and topography imaging [71-74]. X-ray photoelectron spectroscopy (XPS) is recurrently used for oxidation states, stoichiometry, and electronic state determination [75-78]. Complementary characterizations are usually done through Fourier transform infrared spectroscopy (FT-IR) to obtain information on the functional groups and vibrational modes on the corrosion inhibitors. Similarly, ultraviolet-visible spectroscopy (UV-VIS) helps to elucidate functional groups, electronic transitions, and optical band gaps.

Corrosion inhibitors can be classified in the manner they inhibit corrosion: cathodic, anodic, or mixed-type inhibitors [79-81]. Cathodic corrosion inhibitors decrease the corrosion potential, towards lower values, inhibiting the reactions that take place at the cathode, such as oxygen reduction and hydrogen evolution. Anodic corrosion inhibitors move the corrosion potential towards higher values and interact with the reactive sites on the metal surface, passivating them. Mixed-type inhibitors are those that cannot be classified as cathodic or anodic [79-81]. These inhibitors can protect the metal surface in three possible manners: physisorption, chemisorption, and film formation. Physisorption is motivated by the electrostatic interaction between inhibitor molecules and the metal surface, whereas chemisorption is due to donor-acceptor interactions between vacant orbitals on the metal surface and free electron pairs in the inhibitor [79-81]. Lastly, film formation provides the metal surface with a physical barrier from the corrosive media, protecting it from corrosive attacks. 


\subsection{Adsorption Mechanism and Quantum Chemistry Methods}

Phytochemicals present in plant extracts are used as corrosion inhibitors since the inhibition effect is due to the adsorption of the inhibitor molecules on the metal surface, providing the metal with a protective film by blocking the active sites. Consequently, this coverage is less reactive than the blank surface. Several organic compounds coming from natural sources, such as (-)-epicatechin gallate, catechin, or (-)-epicatechin and vallinin, have been proposed since their compounds exhibit some properties argued as requirements to act as corrosion inhibitors. Heteroatoms, substituted aromatic rings, and $\pi$ electrons are claimed to promote the adsorption of the corrosion inhibitor molecules [82-86]. Moreover, some polar functional groups make the inhibitor more soluble in common corrosive media and tend to act as the adsorption sites of the corrosion inhibitor molecule.

Characterization of corrosion inhibitor adsorption on the metal surface by means of Gibbs adsorption energy $\Delta \mathrm{G}^{\circ}$ ads is sometimes complemented by theoretical studies. Accordingly, several theoretical frameworks have been used through the years [87-92]. Certainly, the density functional theory (DFT) is the most recurrently used method since it provides reliable results in affordable computational time. The simplest approach considers the molecules of the most relevant constituents. From the optimized structures of these molecules, several structural, electronic, thermodynamic, and chemical properties can be obtained. $\mathrm{E}_{\mathrm{HOMO}}, \mathrm{E}_{\mathrm{LUMO}}$, energy gap, electronegativity, global hardness, Fukui reactivity indices, and fraction of electron transferred from the corrosion inhibitor molecule to the targeted metal are a group of quantum chemical parameters commonly obtained through methods within DFT.

More robust theoretical studies include the adsorption of corrosion inhibitor molecules in the targeted metal. Two approaches are usually adopted: periodic surfaces [14,93-95] and clusters [96-103]. Free binding energy $G_{\text {bind }}$ has been proven to be comparable with Gibbs adsorption energy $\Delta \mathrm{G}^{\circ}$ ads experimentally obtained. Calculations on DFT are complemented with solvent models, implicit and explicit, and corrections to total energy due to dispersion interactions. Along with DFT, molecular dynamics (MD) is another theoretical framework employed to study the adsorption of corrosion inhibitor molecules. With this method, it is possible to study explicit interactions among corrosion inhibitor molecules, corrosion medium molecules, and the metal surface. In order to obtain a global overview of the adsorption mechanism, thermodynamic variables such as temperature and number of molecules can be studied as well.

To provide a broad outlook on the extracts that have been recently evaluated to act as corrosion inhibitors, the following sections detail information regarding these substances. Extracts, showing good corrosion inhibition properties, are divided in terms of the targeted metal.

\section{Plant-Based Corrosion Inhibitors for Mild Steel}

Steel is the most used metal to test corrosion inhibition due to its innumerable applications. The current section deepens on the most recent reports of plant extracts evaluated for their use as corrosion inhibitors on steel.

Table 1 shows the equations to determine the inhibition efficiency (IE) by different techniques.

Table 1. Equation to determine the inhibition efficiency.

\begin{tabular}{cc}
\hline Technique & Equation \\
\hline EIS [104] & $I E(\%)=\left(1-\left(\left(R_{\mathrm{p}}\right)_{\text {blank }} /\left(R_{\mathrm{p}}\right)_{\text {inhibitor }}\right) * 100\right.$ \\
PP [105] & $I E(\%)=\left[1-\frac{\text { icorr }}{\text { icorrBlank }}\right] \times 100$ \\
WL $[106]$ & $I E(\%)=\left(\left(\mathrm{W}_{0}-\mathrm{W}_{1}\right) /\left(\mathrm{W}_{0}\right)\right) * 100$ \\
\hline
\end{tabular}

$R_{p}$ is a polarization resistance-with inhibitor, it is $\left(R_{p}\right)_{\text {inhibitor, }}$, and without it, it is $\left(R_{p}\right)_{\text {blank }} ; i_{\text {corr }}$ is the current density with and without inhibitor; and $W_{0}$ and $W_{i}$ are the weight loss values in absence and presence of the inhibitor, respectively. 
In order to complement the description on the corrosion inhibition provided by the techniques introduced above, several authors include the study of the adsorption of corrosion inhibitor molecules on the metal surface [96,107-109]. Several adsorption isotherm models have been proposed to describe the adsorption mechanism of organic inhibitors on the metal surface. The most appropriated model is the one that best fits the experimental values. The following table (Table 2) summarizes the most used adsorption isotherm models. In Table $2, C_{R}$ is the concentration of the inhibitor, $\theta$ is the degree or surface coverage of inhibitor, and $K_{a d s}$ is adsorption equilibrium constant. In most cases [2,110-113], the model that best fits to extracts as corrosion inhibitors on metals is the Langmuir isotherm. Adsorption equilibrium constant $K_{a d s}$ is directly related to Gibbs adsorption energy $\Delta \mathrm{G}^{\circ}$ ads by the equation

$$
\Delta G_{a d s}^{\circ}=-55.5 R T \ln K_{a d s}
$$

where $R$ is the universal gas constant, $T$ is the absolute temperature, $K_{a d s}$ is the adsorption equilibrium constant, and 55.5 is the water solution concentration in $\mathrm{mol} / \mathrm{L}$ units. The negative sign of $\Delta G^{\circ}$ ads denotes the spontaneous adsorption of the corrosion inhibitor molecules on the metal surface. Values below $-40 \mathrm{~kJ} / \mathrm{mol}$ are related to chemisorption, ranging from -40 to $-20 \mathrm{~kJ} / \mathrm{mol}$ to mixed physisorption-chemisorption regime and above $-20 \mathrm{~kJ} / \mathrm{mol}$ to physisorption [114-120].

Table 2. Main adsorption isotherm models.

\begin{tabular}{ccc}
\hline Model & Adsorption Isotherm & Reference \\
\hline langmuir & $\frac{C_{R}}{\theta}=\frac{1}{K_{a d s}}+C_{R}$ & {$[121,122]$} \\
temkin & $\theta=\ln C_{R}+K_{a d s}$ & {$[121,123,124]$} \\
freundlish & $\log \theta=n \log C_{R}+\log K_{a d s}$ & {$[124,125]$} \\
flory-huggins & $\log \frac{\theta}{C_{R}}=b \log (1-\theta)+\log K_{a d s}$ & {$[125]$} \\
frumkin & $\log C_{R} \frac{\theta}{1-\theta}=2 \alpha \theta+2.303 \log K_{a d s}$ & {$[121]$} \\
el-awady & $\log \frac{\theta}{1-\theta}=y \log C_{R}+\log K, K_{a d s}=K^{1 / y}$ & {$[121,126]$} \\
\hline
\end{tabular}

Table 3 summarizes the maximum corrosion inhibition efficiency achieved with several plant extracts. It is pertinent to mention that, under testing conditions, plant extracts listed in Table 3 exhibited relevant corrosion inhibition efficiencies, ranging from 64.24 to $98.8 \%$, reported for Ipomoea batatas extract [127] and Glycyrrhiza glabra (Persian liquorice) extract [128], respectively. Moreover, Table 3 includes the solvent used to obtain the plant extracts, metal and corrosive medium tested, as well as the experimental characterizations done. As previously discussed, mild steel is the most studied among iron-based alloys (Table 3) and $1 \mathrm{M} \mathrm{HCl}$ is the most used corrosive medium to test corrosion inhibitor (Table 3).

As discussed previously, all parts of a plant can be used to obtain extracts. For instance, Al Hasan and coworkers studied stem aqueous extract of Bacopa monnieri and Lawsonia inermis (henna) on low carbon steel in a solution of $0.5 \mathrm{M} \mathrm{NaOH}$ [25]. The extract was obtained from $10 \mathrm{~g}$ powder of Bacopa monnieri and $5 \mathrm{~g}$ of henna and tested at inhibitor concentrations of $0.5,1$, and $2 \%$. The joint work of this stem extract produced a mixed type inhibitor of considerable corrosion inhibition efficiency. The authors found a maximum inhibition efficiency about $80 \%$ by the PP technique. Moreover, weight loss measurements resulted in an inhibition efficiency of $65 \%$ (Table 3 ). 
Table 3. Basic information and parameters obtained with several plant extracts evaluated as corrosion inhibitors in steel: plant, extraction solvent, metal, and corrosive medium used for corrosion inhibition performance tests; temperature and concentration $C$ test ranges; maximum inhibition efficiency obtained ( $\eta_{\text {max }}$ ); and characterizations reported are included.

\begin{tabular}{|c|c|c|c|c|c|c|c|c|}
\hline Plant & Extraction Solvent & Metal & Corrosive Medium & Temperature (K) & $\mathrm{C}$ & Characterization & $\eta_{\max }(\%)$ & Reference \\
\hline ananas comosus & Water & Low-carbon steel & $1 \mathrm{M} \mathrm{HCl}$ & $308-338$ & $1000 \mathrm{ppm}$ & WL, EIS, PP, UV-VIS, SEM & 97.6 & [136] \\
\hline artemisia herba-alba & Water & Stainless steel & $1 \mathrm{M} \mathrm{H}_{3} \mathrm{PO}_{4}$ & $298-353$ & $1 \mathrm{~g} / \mathrm{L}$ & EIS, SEM-EDS, GC-MS & 88 & [137] \\
\hline bacopa monnieri/lawsonia inermis & Water & Low-carbon steel & $0.5 \mathrm{M} \mathrm{NaOH}$ & - & $0.4-0.8 \mathrm{~g} / \mathrm{L}$ & WL, PP & 80 & [25] \\
\hline camellia sinensis & Water & Carbon steel & $3.5 \% \mathrm{NaCl}$ & - & $0.5-2 \%$ & LPR, LC-MS & 80 & [82] \\
\hline cryptocarya nigra & $\begin{array}{l}\text { Hexane, dichloromethane, } \\
\text { methanol }\end{array}$ & Mild steel & $1 \mathrm{M} \mathrm{HCl}$ & - & $10-1000 \mathrm{mg} / \mathrm{L}$ & PP, EIS, SEM-EDS, FT-IR, UV-VIS & 91 & [135] \\
\hline dioscorea septemloba & Ethanol & Carbon steel & $1 \mathrm{M} \mathrm{HCl}$ & 303.15 & $0.1-2.0 \mathrm{~g} / \mathrm{L}$ & NMR, EIS, FT-IR, SEM & 72 & [138] \\
\hline eucalyptus & Water & Mild steel & $1 \mathrm{M} \mathrm{HCl}$ & - & $800 \mathrm{ppm}$ & PP, WL, EIS, FT-IR, UV-VIS, SEM, AFM & 88 & [127] \\
\hline eucalyptus globulus & Water & Low-carbon steel & $0.5 \mathrm{M} \mathrm{H}_{2} \mathrm{SO}_{4}$ & - & $100-600 \mathrm{mg} / \mathrm{L}$ & WL, EIS, AFM, FT-IR, SEM, EFM & 93.09 & [129] \\
\hline euphorbia heterophylla llinneo & Water & Mild steel & $1.5 \mathrm{M} \mathrm{HCl}$ & - & $1 \mathrm{~g} / \mathrm{L}$ & PP & 69 & [139] \\
\hline ficus tikoua & Water & Carbon steel & $1 \mathrm{M} \mathrm{HCl}$ & - & $200 \mathrm{mg} / \mathrm{L}$ & FT-IR, EIS, PP, SEM & 95.8 & [130] \\
\hline glycyrrhiza glabra & Water & Mild steel & $1 \mathrm{M} \mathrm{HCl}$ & - & $200-600 \mathrm{ppm}$ & EIS, PP, FT-IR, AFM & 88 & [128] \\
\hline ipomoea batatas & $N$-hexane & Galvanized steel & $1 \mathrm{M} \mathrm{HCl}$ & $308.15-338.15$ & $0.7 \mathrm{~g} / \mathrm{L}$ & FT-IR, EIS & 64.26 & [140] \\
\hline juglans regia & Water & Mild steel & $3.5 \mathrm{wt} \% \mathrm{NaCl}$ & - & $1000 \mathrm{ppm}$ & PP, EIS, FR-IR, SEM & 94.2 & [141] \\
\hline luffa cylindrica & Ethanol & Mild steel & $1 \mathrm{M} \mathrm{HCl}$ & $303-333$ & $1 \mathrm{~g} / \mathrm{L}$ & WL, PP, EIS, FT-IR & 87.98 & [142] \\
\hline nicotiana tabacum & Water & Q235 steel & $0.1 \mathrm{M} \mathrm{NaOH}$ & - & $34 \mathrm{mg} / \mathrm{L}$ & PP, FT-IR, XPS, SEM, XRD & 83.9 & [143] \\
\hline olea europaea & $\begin{array}{l}\text { Methanol, ethyl acetate, } \\
\text { dichloromethane, hexane }\end{array}$ & Mild steel & $0.1 \mathrm{M} \mathrm{NaOH}+0.5 \mathrm{M} \mathrm{NaCl}$ & - & $200-800 \mathrm{mg} / \mathrm{L}$ & EIS, GC-MS & 91.9 & [134] \\
\hline papaver somniferum & Ethanol & AISI 304 stainless steel & $0.2 \mathrm{M} \mathrm{HCl}$ & $298.15-318.15$ & $100-500 \mathrm{ppm}$ & AFM, SEM-EDS & 88 & [144] \\
\hline pterocarpus santalinoides & $\begin{array}{l}\text { Water, ethanol, and } \\
\text { methanol }\end{array}$ & Low carbon steel & $1 \mathrm{~mol} / \mathrm{dm}^{3} \mathrm{HCl}$ & $298.15-333.15$ & $0.7 \mathrm{~g} / \mathrm{L}$ & EIS, PP, LPR, SEM-EDAX, AFM & 90 & [145] \\
\hline rosa canina & Water & Mild steel & $1 \mathrm{M} \mathrm{HCl}$ & - & $200-800$ ppm & EIS, UV-VIS, PP, SEM & 86 & [146] \\
\hline saraca ashoka & Water & Mild steel & $0.5 \mathrm{M} \mathrm{H}_{2} \mathrm{SO}_{4}$ & - & $25-100 \mathrm{mg} / \mathrm{L}$ & WL, EIS, PP, SEM, UV-VIS, FT-IR, AFM & 93.09 & [131] \\
\hline tamarindus indiaca & Water & Mild steel & $3.5 \% \mathrm{NaCl}$ & - & $300-1000 \mathrm{ppm}$ & FE-SEM, AFM, EIS, FT-IR, GI-XRD & 96 & [147] \\
\hline tamarindus indiaca & Water & Mild steel & $3.5 \% \mathrm{NaCl}$ & - & $1000 \mathrm{ppm}$ & $\begin{array}{l}\text { FT-IR, UV-VIS, XRD, TGA, Raman, EIS, } \\
\text { FE-SEM }\end{array}$ & - & [132] \\
\hline taraxacum officinale & Water/ethanol & Carbon steel & Seawater & $295.15-328.15$ & $100-400 \mathrm{mg} / \mathrm{L}$ & WL, PP, EIS, SEM, FT-IR, UV-VIS & 94.3 & [133] \\
\hline tinospora crispa & Water, acetone/water & Mild steel & $1 \mathrm{M} \mathrm{HCl}$ & - & 800-1000 ppm & WL, EIS, SEM & 80 & [111] \\
\hline tithonia diversifolia & Water & Mild steel & $1 \mathrm{M} \mathrm{HCl}$ & - & $0.1-0.7 \%$ & WL, EIS, PP, FT-IR & 94.55 & [148] \\
\hline zingiber officinale & Methanol & Mild steel & $1 \mathrm{M} \mathrm{HCl}$ & $298.15-328.15$ & $100 \mathrm{ppm}$ & PP, EIS, FR-IR, UV-VIS, AFM & 92.5 & [149] \\
\hline ziziphora & Water & Mild steel & $1 \mathrm{M} \mathrm{HCl}$ & - & $200-800 \mathrm{ppm}$ & FT-IR, UV-VIS, EIS & 93 & [150] \\
\hline
\end{tabular}


Leaf extracts are also used to obtain extracts with corrosion inhibition properties. For instance, green Eucalyptus leaf extract as corrosion inhibitor, in mild steel in $1 \mathrm{M} \mathrm{HCl}$ corrosive medium, was evaluated by Dehghani, Bahlakeh, and Ramazanzadeh [127]. The maximum corrosion inhibition achieved with this aqueous extract is $88 \%$ at $800 \mathrm{ppm}$ concentration (Table 3). EIS showed increment of charge transfer resistance as the extract concentration increased. On the basis of PP tests, the mixed nature of the corrosion inhibition of the Eucalyptus leaf extract was evidenced. SEM and AFM tests were used to demonstrate that higher concentrations increased the number of protective molecules adsorbed on the metal surface. Gibbs adsorption energy $\Delta \mathrm{G}^{\circ}$ ads, calculated by fitting the Langmuir isotherm, showed that the inhibitor concentration increased the chemisorption component of this mixed type inhibitor.

The aqueous green tea (Camellia sinensis) extract was evaluated by Pradipta and coworkers as a corrosion inhibitor on carbon steel in a 3.5\% NaCl corrosive medium [82]. Green tea was chosen as substances with multiple polar atoms and electron-rich bonds, such as the natural antioxidants contained in this plant, are potential mixed-type corrosion inhibitors. Through linear polarization resistance measurements, green tea extract exhibited a similar corrosion inhibition efficiency, ranging from 51 to $70 \%$, in comparison of commercial calcium nitrite corrosion inhibitor at similar concentrations (Table 3). At equal volumes, the green tea extract exhibited a higher corrosion inhibition efficiency of about $75-80 \%$ in comparison of the commercial corrosion inhibitor. On the basis of liquid chromatography-mass spectrometry, (-)-epigallocatechin gallate, (-)-epicatechin gallate, and catechin or (-)-epicatechin are supposed to form the mixed-type corrosion inhibiting film.

The Eucalyptus globulus leaves extract has been tested by Haldhar and Prasad [129] on low carbon steel immersed in a $0.5 \mathrm{M}$ sulfuric acid $\left(\mathrm{H}_{2} \mathrm{SO}_{4}\right)$ solution. Corrosion inhibition properties were evaluated using weight loss and EIS (Table 3). This investigation shows that the Nyquist diagram reached a maximum value in the real part of the impedance of about $250 \Omega \mathrm{cm}^{2}$. This extract obtained its strongest corrosion inhibition of $93.09 \%$ at a concentration of $600 \mathrm{mg} / \mathrm{L}$. Through UV-VIS spectroscopy, the formation of coordination bonds between inhibitor molecules and $\mathrm{Fe}^{2+}$ was verified. SEM and AFM tests are used to confirm the formation of the corrosion protective film on the metal surface. Various functional groups containing heteroatoms and unsaturation in the phytochemical constituents of the plant extract are studied by using FT-IR and proton-nuclear magnetic resonance $\left({ }^{1} \mathrm{H}\right.$ NMR) techniques, respectively.

Another aqueous extract tested to act as corrosion inhibitor on carbon steel in $1 \mathrm{M} \mathrm{HCl}$ corrosive solution is the Ficus tikoua leaf extract [130]. According to Wang and coworkers, PP curves obtained agree with a mixed-type inhibitor. The highest corrosion inhibition efficiency achieved, of about $95.8 \%$, was obtained at $298 \mathrm{~K}$ with a $200 \mathrm{mg} / \mathrm{L}$ concentration (Table 3). Authors argued that the complex composition of the extract hinders fitting an adsorption isotherm to calculate Gibbs adsorption energy $\Delta \mathrm{G}^{\circ}$ ads. Through SEM imaging, the surface smoothness gained by applying the extract in comparison of the blank surface was confirmed.

In addition, fruit extracts have been proposed as corrosion inhibitors. The corrosion inhibition performance of the Rosa canina fruit aqueous extract was evaluated on mild steel in a $1 \mathrm{M} \mathrm{HCl}$ electrolyte by Sanaei and coworkers in 2019. The properties of the extract were evaluated by means of electrochemical impedance spectroscopy, UV-VIS spectroscopy, and SEM imaging. SEM images confirmed the lower degradation obtained by applying the Rosa canina fruit aqueous extract on mild steel. The maximum corrosion inhibition efficiency achieved, of about $86 \%$, was obtained with an $800 \mathrm{ppm}$ concentration (Table 3). Moreover, the extract behaved as a mixed-type inhibitor, with both cathodic and anodic reactions. It has been suggested that physically adsorbed molecules (extract) bind to metal in local cathodes and the dissolution of the metal is delayed when the cathodic reaction is prevented, while molecules chemically adsorbed protect the anodic areas.

As studied by Saxena and coworkers, Saraca ashoka seed aqueous extract on mild steel in $0.5 \mathrm{M} \mathrm{H}_{2} \mathrm{SO}_{4}$ behaves as a good corrosion inhibitor [131]. According to electrochemical impedance spectroscopy and weight loss measurements, a maximum corrosion inhibition efficiency of about 95.48 
and $93.09 \%$, respectively, was achieved with a $100 \mathrm{mg} / \mathrm{L}$ extract concentration (Table 3). The formation of a protective film on the metal surface was confirmed by AFM and SEM imaging. For this extract, the Langmuir adsorption model was a better fit. The study concluded that Saraca ashoka seed aqueous extract behaves as a mixed-type corrosion inhibitor.

Akbarzadeh and co-workers studied an intelligent self-healing anticorrosion coating using nanocarriers on the basis of a graphene oxide (GO) nanoplatform with Tamarindus indiaca extract (Ti.E) and $\mathrm{Zn}^{2+}$ ions, labeled as GON-Ti.E-Zn, obtained through a green assisted route [132]. Raman spectroscopy results revealed the defect creation on the GO nanosheets due to the Ti.E molecule adsorption. The adsorption of Ti.E molecules on GO sheets was confirmed by several experimental techniques, including XRD, FT-IR, and UV-VIS. EIS spectra of the epoxy ester coating with and without artificial scratches along with salt spray observation demonstrated the achievement of an active barrier system, exploiting simultaneously Tamarindus indiaca extract and Zn-modified GO nanocarriers. In fact, the molecules released within GO, previously contained in Ti.E and zinc cations, are assumed to be the components responsible to build the protective layer. In this case, corrosion inhibition efficiency is not reported [132].

The aqueous extract of Tinospora crispa as corrosion inhibition on mild steel in $1 \mathrm{M} \mathrm{HCl}$ was evaluated by Hussin and co-workers [111]. Weight loss, EIS, and PP methods are used for deepening into the corrosion inhibitor properties of the extract. The maximum inhibition, of about $70-80 \%$, was obtained with an 800 ppm concentration (Table 3). Another extract, obtained with acetone-water as extraction solvent, has been studied as well. In this case, the maximum inhibition efficiency was obtained with a $1000 \mathrm{ppm}$ concentration. The Langmuir adsorption isotherm was used to obtain a Gibbs adsorption energy $\Delta \mathrm{G}^{\circ}$ ads of about $-21.87 \mathrm{~kJ} / \mathrm{mol}$ with the aqueous extract and $-20.25 \mathrm{~kJ} / \mathrm{mol}$ with acetone-water extract. The spontaneous physisorption process was determined by these calculations. SEM imaging confirmed the protection provided by the extracts on the mild steel surface.

Deyab and Guibal studied the Taraxacum officinale extract, obtained in a 2:3 aqueous/ethanol solution solvent, on carbon steel in seawater to test desalinization plant conditions [133]. This extract, according to the weight loss method, as well as PP and EIS tests, showed high inhibition efficiencies of up to $94.3 \%$ (Table 3). PP data showed that the extract behaved mostly as an anodic inhibitor. The inhibition mechanism was found through a modified Langmuir adsorption isotherm, as physisorption of the compounds contained in the extract. Moreover, Nyquist plots showed that the inhibition efficiency increased as the extract concentration increased. From all the above, authors proposed Taraxacum officinale extract as a potential corrosion inhibitor for cooling systems and desalination plants.

\subsection{Solvent Effect}

Since several solvents can be used to obtain extracts, the behavior of the inhibition efficiency of the different extract obtained is another topic of interest. This synergistic effect can be related to its higher effectiveness to extract the phytochemicals responsible for the inhibition effect. Thus, different solvents must be tested in order to determine the one that obtains the extract with the best performance [4]

The investigation of olive leaf (Olea europaea) extract performed by Ben et al. [134], tested on mild steel in a $0.1 \mathrm{M} \mathrm{NaOH}+0.5 \mathrm{M} \mathrm{NaCl}$ corrosive solution, showed that inhibition efficiency increases as the polarity of the extraction solvent increases. They found that the inhibition efficiency decreased as follows: methanol, ethyl acetoacetate, hexane, and dichloromethane. The maximum inhibition efficiency was obtained with the methanol extract of about $91.9 \%$ (Table 3). On the basis of gas chromatography-mass spectrometry analysis, the authors suggested that the inhibition activity could be due to the presence of nitrogen, oxygen, and $\pi$-electrons. The extract was found to be a phenol- and flavonoid-rich substance. According to PP studies, olive leaf extract is a mixed-type inhibitor. EIS and Mott-Schottky analyses agreed well with PP results.

On the other hand, Faiz et al. used the Cryptocarya nigra extracts obtained with three different solvents (hexane, dichloromethane, and methanol) and three alkaloids ( $N$-methylisococlaurine, $\mathrm{N}$-methyllaurotetanine, and atherosperminine) isolated from the dichloromethane extract to act 
as corrosion inhibitors on mild steel in $1 \mathrm{M} \mathrm{HCl}$. These alkaloids were chosen by their antioxidant properties and their poly-phenolic groups, expected to assist the protection of the metal surface [135]. It is interesting that the Cryptocarya nigra dichloromethane extract is a potent corrosion inhibitor and $N$-methyllaurotetanine achieved the highest efficiency of about $\eta_{\max } 91.05$ and 88.05\%, respectively (Table 3). The alkaloid behaves as a good corrosion inhibitor since it contains nitrogen. Moreover, the authors argued that $N$-methyllaurotetanine has more oxygenated functional groups in comparison to the others and a rigid structure, being more favorable to protect the metal surface. According to Gibbs adsorption energy ( $\Delta \mathrm{G}^{\circ}$ ads $)$ obtained by Langmuir adsorption isotherm plots, the most efficient extracts were adsorbed on the metal surface via physisorption [135].

The crude extract of Pterocarpus santalinoides leaves, studied by Ahanotu et al. [145], has been shown to be effective in inhibiting the corrosion in low carbon steel in a $1 \mathrm{~mol} / \mathrm{dm}^{3} \mathrm{HCl}$ solution. Results obtained through EIS, PP, and LPR measurements showed that the protection efficiency of the Pterocarpus santalinoides leaf extract improves with an increase in dosage and temperature. The metal surface has been protected by over $90 \%$ at $333.15 \mathrm{~K}$ (Table 3 ). The authors suggest that the extract behaves as a mixed-type corrosion inhibitor according to its PP results. The lack of roughness in AFM measurements reveal that the surface is not deeply penetrated with the use of Pterocarpus santalinoides leaf extract, in contrast with the corrosion showed without using it. The performance of the extracts obtained with different extraction solvents follows the order ethanolic $>$ methanolic $>$ aqueous. The authors suggested that this tendency is a consequence of the better efficiency of ethanol and methanol to extract the flavonoids contained in Pterocarpus santalinoides leaves, compounds known to act as good inhibitors in carbon steel [4].

Akbarzadeh et al. [147] studied the performance of green corrosion inhibitor obtained from the Tamarindus indiaca (TAM) extract mixed with zinc nitrate (ZS). The metal tested was mild steel in $3.5 \% \mathrm{NaCl}$ as corrosion medium. Electrochemical impedance spectroscopy results showed the synergistic behavior and 96\% corrosion inhibition efficiency in TAM with 300 ppm and ZS 700 ppm after a $24 \mathrm{~h}$ immersion (Table 3). Polarization spectrum results exhibited the dominant behavior of the anodic depression in the mixture of TAM and ZS. Field emission SEM and grazing incidence XRD images confirmed the formation of a uniform protective layer.

\subsection{Temperature and Immersion Time Effect}

Temperature has an important influence on the phenomenon of corrosion in metal surfaces. It is possible to modify the interaction between the corrosive medium and the metal surface in the presence of the extract with inhibitors. Some extracts exhibit an increasing inhibition efficiency tendency towards higher temperatures [151]. However, other extracts show different behaviors. Thus, the evaluation of the inhibition efficiency as a function of the temperature is important since every extract could perform differently [152-157]. Similarly, the immersion time is another factor that could modify the inhibition efficiency, and consequently some authors have evaluated it as well [158-161].

For instance, Wang et al. evaluated the corrosion inhibition performance of the tobacco rob (Nicotiana tabacum) aqueous extract in Q235 steel in artificial seawater with a $0.1 \mathrm{M} \mathrm{NaOH}$ solution as corrosive medium [143]. Nicotine was found to be the main compound responsible of the corrosion inhibition effect. Inhibition efficiency increased as the extract concentration and temperature increased. The maximum corrosion inhibition performance, inhibition efficiency of about $83.9 \%$, was obtained with a $100 \mathrm{mg} / \mathrm{L}$ extract concentration at 333.15 K (Table 3). According to XRD spectra and SEM images, without the extract, $\mathrm{CaCO}_{3}$ and $\mathrm{CaSO}_{4}$ deposit on the metal surface. In contrast, the extract retarded the growth of both deposits. Authors suggest that the growth of $\mathrm{CaCO}_{3}$ and crystal $\mathrm{CaSO}_{4}$ is blocked by chelating due to the water-soluble -OH group contained in the extract. XPS indicated that the corrosion inhibition was due to chemisorption on the metal surface.

As discussed previously, all parts of plants can be used to obtain extracts. Pineapple (Ananas comosus) stem extracts were evaluated by Mobin, Basik, and Aslam as a corrosion inhibitor on low-carbon steel immersed in $1 \mathrm{M} \mathrm{HCl}$ [136]. A high maximum inhibition efficiency of about $97.6 \%$ was obtained 
with this extract at a $1000 \mathrm{ppm}$ concentration and $338 \mathrm{~K}$ temperature (Table 3). A dependence on the electrolyte temperature and inhibitor concentration was observed, showing that both properties increase towards higher temperatures and concentrations, respectively. The adsorption was found, according to the Langmuir adsorption isotherm fitted, as mixed type physisorption-chemisorption. Higher temperature leads to chemisorption, in agreement with the tendency observed for inhibition efficiency. Results obtained through WL, EIS, and PP methods show consistency among them [136]. A smoother metal surface is obtained by the action of the inhibitor extract, as shown by SEM images.

The Tithonia diversifolia flower extract as a corrosion inhibitor on mild steel in $1 \mathrm{M} \mathrm{HCl}$ was tested through electrochemical impedance spectroscopy, weight loss, and potentiodynamic polarization techniques by Divya et al. (2019). The temperature increased the inhibition efficiency up to $325 \mathrm{~K}$, achieving a maximum inhibition efficiency of about $94.55 \%$, whereas it decreased at higher temperatures (Table 3). According to the PP curves, the Tithonia diversifolia flower extract acted as a mixed type inhibitor. Optical electron studies agreed with the strong adsorption inhibitor molecules on the mild steel surface.

Anyiam et al. [140] investigated the sweet potato tuber (PMS) extract, obtained with $n$-hexane as solvent, as corrosion inhibitor on the galvanized steel surface in acidic media $(1 \mathrm{M} \mathrm{H} \mathrm{Cl})$ at different temperatures and immersion times. Gravimetric and potentiodynamic polarization measurements obtained a maximum inhibition efficiency of $64.26 \%$, obtained at a concentration of $0.7 \mathrm{~g} / \mathrm{L}$. Moreover, PP studies showed that the PMS extract behaved as a mixed-type inhibitor. They observed that the corrosion rate increased at all corrosion inhibitor concentrations as temperature increased. In addition, it indicated physical adsorption of the PMS molecules on the galvanized steel according to Gibbs adsorption energy values $\left(\Delta \mathrm{G}^{\circ}\right.$ ads $)$ obtained through the Langmuir adsorption isotherm, lower than $-20 \mathrm{~kJ} / \mathrm{mol}$.

Another extract, tested by Gadow and Motawea, was the one obtained with ginger roots and methanol as solvent [149]. They mentioned that the extract was formed mostly by six organic compounds: gingerol, zingiberene, $\beta$-bisabolene, $\alpha$-farnesene, shogaol, and $\beta$-sesquiphellandrene. Through weight loss measurements, the authors obtained an inhibition efficiency of about $92.5 \%$ at a $100 \mathrm{ppm}$ concentration (Table 3). The inhibition efficiency increased up to $94 \%$ with $200 \mathrm{ppm}$ at $298.15 \mathrm{~K}$. Moreover, the evaluation of the inhibition efficiency at different temperatures showed that the inhibition efficiency decreased as the temperature increased. PP curves indicated that the extract behaved as a mixed-type inhibitor and followed a physical adsorption that was well fitted to a Langmuir isotherm.

Buyuksagis and Dilek (2019) [144] observed the use of Papaver somniferum leaves as a corrosion inhibitor on AISI 304 stainless steel in $0.2 \mathrm{M} \mathrm{HCl}$. The increase in temperature reduced the corrosion inhibition on steel. They attributed this observation to the competition between water molecules and adsorbed inhibitor molecules. A $500 \mathrm{ppm}$ concentration was found to be the best inhibitor, achieving $88 \%$ of inhibition efficiency (Table 3). AFM, SEM, and energy-dispersive X-ray spectroscopy (EDS) were used to investigate a metal surface protected with the inhibitor. The metal surface covered with the inhibitor was protected with a thick dense film. The inhibitor was physically adsorbed on the metal surface, as confirmed by the Langmuir isotherm. Moreover, the Papaver somniferum leaf extract was found to behave as a mixed-type inhibitor.

Similarly, Emori et al. observed that Dioscorea septemloba on carbon steel in a $1 \mathrm{M} \mathrm{HCl}$ solution reduced its inhibition properties as temperature increased. Two extracts were obtained, with water and ethanol as solvents. Nuclear magnetic resonance was used to identify the 28 compounds present in ethanol extract. SEM and FT-IR techniques confirmed the adsorption of the extract molecules on the metal surface and the formation of the protective film. The inhibition properties were due to their multiple aromatic rings and heteroatoms found in the compounds. The inhibitor was found as a mixed-type inhibitor according to the EIS tests, achieving $72.1 \%$ inhibition efficiency at $2.0 \mathrm{~g} / \mathrm{L}$ [138] (Table 3). 
Furthermore, Ogunleye et al. [142] observed that the inhibition efficiency of Luffa cylindrica extract on mild steel in a $0.5 \mathrm{M} \mathrm{HCl}$ solution decreases with temperature. In contrast, inhibition efficiency increases as the inhibitor concentration increases. Tanines, flavonoids, phenol, tannins, and alkanol groups are found in the extract by means of gas chromatography-mass spectrometry (GC-MS) and FT-IR tests (Table 3).

The aqueous extract of Artemisia herba-alba on stainless steel in $1 \mathrm{M} \mathrm{H}_{3} \mathrm{PO}_{4}$ corrosive media was tested by Boudalia and coworkers [137]. They found that the highest inhibition efficiency, of about $88 \%$, was achieved at $1 \mathrm{~g} / \mathrm{L}$ concentration and $298 \mathrm{~K}$ (Table 3 ). Authors suggested that the decreasing inhibition efficiency as the temperature increased can be understood as a result of the higher dissolution achieved at higher temperatures. The tested inhibitor obeyed the Langmuir adsorption isotherm model. In addition, the calculated Gibbs adsorption energy $\left(\Delta \mathrm{G}^{\circ}\right.$ ads $)$ agreed with a physically adsorbed inhibitor. The protective effect of the Artemisia herba-alba aqueous extract on stainless steel was confirmed by means of SEM/EDS micrography.

The performance of Glycyrrhiza glabra root extract on the corrosion inhibition on mild steel in $1 \mathrm{M} \mathrm{HCl}$ electrolyte was investigated by Alibakhshi et al. [162] through EIS and PP tests. EIS results revealed that the inhibition efficiency increased as the concentration and immersion time increased. A maximum inhibition efficiency of about $88 \%$ was achieved at $800 \mathrm{ppm}$ concentration after $24 \mathrm{~h}$ immersion (Table 3). Atomic force microscopy confirmed the lower degradation shown on the mild steel treated with licorice extract.

Similarly, Akinbulumo et al. investigated the Euphorbia heterophylla Linneo extract on mild steel in a $1.5 \mathrm{M} \mathrm{HCl}$ corrosive medium [139]. The gravimetric method was used to measure the inhibition efficiency and corrosion rate. Flory-Huggins adsorption isotherm was a better fit than Langmuir, El-Awary, and Temkin isotherms. Gibbs adsorption energy $\left(\Delta \mathrm{G}^{\circ}\right.$ ads $)$ values below $-20 \mathrm{~kJ} / \mathrm{mol}$ denoted a physisorption process. The maximum efficiency was obtained at $343 \mathrm{~K}$ of about $69 \%$, since at higher temperatures the efficiency decreased (Table 3). The authors suggest that this behavior was a consequence of the desorption of the inhibitor molecule from the metal surface [139].

Ziziphora leaf extract was proposed as an eco-friendly green inhibitor on mild steel at $1 \mathrm{M} \mathrm{HCl}$ concentration by Dehghani and coworkers [150]. Higher concentrations increased the corrosion inhibition efficiency. Moreover, immersion time showed a dependence on the immersion time, obtaining a maximum inhibition efficiency of about $93 \%$ with $800 \mathrm{ppm}$ concentration and $2.5 \mathrm{~h}$ immersion (Table 3). Gibbs adsorption energy $\left(\Delta \mathrm{G}^{\circ}\right.$ ads $)$ obtained by fitting the Langmuir adsorption isotherm was obtained, ranging from -33 to $-35 \mathrm{~kJ} / \mathrm{mol}$. Thus, Ziziphora leaf extract is a mixed-type physisorption-chemisorption inhibitor.

Haddadi and coworkers, studying the Junglans regia green fruit shell extract as a corrosion inhibitor on mild steel in $3.5 \mathrm{wt} \% \mathrm{NaCl}$ solution, found that the inhibition capacity was promoted with the immersion time up to $48 \mathrm{~h}$ [141]. The maximum inhibition efficiency achieved, of about $94 \%$, was obtained with $1000 \mathrm{ppm}$ (Table 3). PP tests showed that both cathodic and anodic reactions were retarded. Functional groups, such as carboxyl, hydroxyl, and carbonyl, of phenolic compounds of the extract were supposed to be physically and chemically adsorbed on the metal surface. Thus, electrostatic interactions and covalent bonding were responsible for a mixed physisorption-chemisorption process [141].

\subsection{Adsorption Mechanism and Theoretical Characterization}

The previous sections exhibited how the most common studies regarding corrosion inhibition were based on experimental evidence obtained through electrochemical tests, used to study the inhibition efficiency and surface microscopy. To a lesser extent, experimental studies were used to determine the way the inhibitor was adsorbed on the metal surface. Gibbs adsorption energy $\left(\Delta \mathrm{G}^{\circ}{ }_{\text {ads }}\right)$, obtained by adjusting a suitable adsorption isotherm, is probably the most reported amount related to the adsorption mechanism. According to its value, $\Delta \mathrm{G}^{\circ}$ ads denotes physisorption, chemisorption, or mixed physisorption-chemisorption. In order gain deeper insight into adsorption mechanisms on 
steel surfaces, this subsection focuses on theoretical studies used to complement experimental findings. Theoretical characterization, based on structural analysis and molecule-surface interactions, allows for the elucidation of the adsorption mechanism at an atomic level of detail. Basic information obtained by means of theoretical characterizations of several plant extracts as corrosion inhibitors is summarized in Table 4; the main extract constituents and theoretical framework used for their evaluation are listed as well.

Table 4. Theoretical characterization performed for several plant extracts: plant, main extract constituents, and theoretical framework used for their evaluation.

\begin{tabular}{|c|c|c|c|}
\hline Plant & Extract Constituents & Theory & Reference \\
\hline Dioscorea septemloba & Dioscin, $\beta$-sitosterol, dioscorone $\mathrm{A}$, and palmitic acid & DFT, MD & [138] \\
\hline Eucalyptus & $\begin{array}{l}\text { Macrocarpal E, macrocarpal A, eucalyptome, } \\
\text { and ellagic acid }\end{array}$ & DFT, MC, MD & [127] \\
\hline Eucalyptus globulus & Eucalyptol, globulusin-A, and globulusin-B & DFT & [129] \\
\hline Ficus tikoua & $\begin{array}{l}\text { Allantoin, 5-methoxypsoralen, methyl caffeate, } \\
\text { and methyl 4-hydroxycinnamate }\end{array}$ & DFT & [130] \\
\hline Juglans regia & $\begin{array}{l}\text { Coumaric acid, ferulic acid, syringic acid, vanillic } \\
\text { acid, juglone, and myricetin }\end{array}$ & DFT, MC, MD & [141] \\
\hline Glycyrrhiza glabra & $\begin{array}{l}\text { Licochalcone A, licochalcone E, liquiritigenin, } \\
18 \beta \text {-glycyrrhetinic acid, glycyrrhizin, and glabridin }\end{array}$ & DFT, MC, MD & [128] \\
\hline Rosa canina & Ascorbic acid, marein, pectin, and tannin & DFT, MC, MD & [146] \\
\hline Saraca ashoka & Epicatechin & DFT & [131] \\
\hline Tamarindus indiaca & Apigenin, naringenin, eriodyctoyl, and taxifolin & $\mathrm{DFT}, \mathrm{MC}, \mathrm{MD}$ & [147] \\
\hline Tamarindus indiaca & Naringenin, apigenin, eriodictyol, and taxifolin & DFT-D & [132] \\
\hline Ziziphora & Acacetin, chrysin, and thymonin & DFT, MC, MD & [150] \\
\hline
\end{tabular}

Several characteristics on the compounds contained in a certain extract are known to influence the adsorption and, consequently, the inhibition properties. According to Ben Harb et al. [134], molecular size, carbon chain length, conjugated bonding, aromaticity, aptitude of film to be dense or reticulated, resistance of the bond to the metal substrate, number and nature of bonding groups and atoms within a molecule, and an appropriate solubility of phenolic compounds in solvent extraction are expected to affect the inhibition efficiency. Although the authors obtained an efficient corrosion inhibitor with Olea europaea leaf extract, explained by the presence of nitrogen, oxygen heteroatoms, and $\pi$ electrons in the phenol and flavonoid extract content, no more information on the adsorption mechanism was provided.

In contrast, Emori and coworkers reported quantum chemistry studies on the major chemical compounds (dioscin, $\beta$-sitosterol, dioscorone A, and palmitic acid) found for Dioscorea septemloba extract (Table 4) [138]. Calculations were carried out at the RB3LYP/6-311++G(d,p) level within DFT. Energies of the highest occupied molecular orbital (HOMO) and the lowest unoccupied molecular orbital (LUMO), $\mathrm{E}_{\mathrm{HOMO}}$ and $\mathrm{E}_{\mathrm{LUMO}}$, respectively, were used to determine the reactivity of the major components of the extract. They showed, through the HOMO-LUMO energy gap, that the glycoside groups contributed more to the corrosion inhibition performance than the fatty acids. This initial assumption was confirmed by means of molecular dynamics, obtaining binding energies $\left(E_{\text {bind }}\right)$ of the adsorbed molecules on the $\mathrm{Fe}(110)$ surfaces following the order of dioscin $>$ dioscorone $\mathrm{A}>\beta$-sitosterol $>$ palmitic acid. The order found for the number of electrons transferred $(\Delta N)$, as defined by Lukovits, also obeyed the same pattern [163]. Lastly, the authors argued that large molecular sizes of the adsorbed molecules ensure greater coverage and improve metal-inhibitor interactions. Moreover, oxygen heteroatoms and $\pi$ electrons can participate by back-bonding from the $d$-orbitals of Fe on the metal surface, establishing covalent bonds.

Dehghani and coworkers studied theoretically the most relevant molecules present in Eucalyptus extract: macrocarpal E, macrocarpal A, eucalyptome, and ellagic acid (Table 4). The authors determined 
that the $\Delta \mathrm{G}^{\circ}$ ads values within the physisorption-chemisorption regime, ranging from -32 to $-35 \mathrm{~kJ} / \mathrm{mol}$, can be directly compared with binding energies calculated by means of theoretical Monte Carlo (MC) and molecular dynamics simulations on Fe(110) surfaces, water, and Eucalyptus extract molecules, both neutral and mono-protonated. HOMO, LUMO, and Fukui reactivity indices, obtained through DFT calculations, showed that electron-rich regions (around aromatic rings and double bonds) and oxygen heteroatoms could donate their electrons by electrophilic attack to nucleophiles or empty $d$-orbitals of metal atoms, allowing chemisorption. The physical component is previously described as a consequence of electrostatic and van der Waals interactions [127].

Similarly, Haldhar and Prasad studied, by means of DFT calculations, the three main components of the Eucalyptus globulus aqueous extract: eucalyptol, globulusin-A, and globulusin-B (Table 4) [129]. Several global quantum chemical descriptors were used to obtain information regarding the reactivity and the behavior of those compounds in the presence of iron: HOMO-LUMO gap, $\eta$ softness, $\sigma$ chemical hardness, and $\mu$ dipole moment. Authors suggest that these compounds act as Lewis bases and form coordination bonds with the free $d$-orbital of Fe. HOMOs indicate that inhibitor molecules have pairs of electrons available for nucleophilic interactions, via chemisorption, with low carbon steel surface. Physisorption is possible through the electrostatic interaction among heteroatoms and $\mathrm{Fe}^{2+}$ atoms. Back-bonding is possible through $\pi$ electrons of aromatic rings.

Moreover, Wang and coworkers used the global descriptors, obtained at the B3LYP/6-311++G(d,P) level within DFT, introduced above, to study the corrosion inhibition properties on carbon steel of four major components of the Ficus tikoua extract: allantoin, 5-methoxypsoralen, methyl caffeate, and methyl 4-hydroxycinnamate (Table 4) [130]. HOMO and LUMO were used to determine the tendency to donate and to accept electrons of these molecules. Moreover, smaller HOMO-LUMO gap was found to be related to higher corrosion inhibition efficiency. Thus, 5-methoxypsoralen is expected to play the most important role in the inhibition properties of Ficus tikoua extract due to its small energy gap. Furthermore, this molecule has a high dipole moment also associated with its high corrosion inhibition performance. Electrostatic potential (ESP) maps were used to describe electrophilic and nucleophilic activities. Nucleophilic regions were mainly distributed near heteroatoms or O-heterocycles, expected to form covalent bond with Fe atoms.

The theoretical study of the aqueous extract of Juglans regia was obtained by means of DFT calculations, at the B3LYP/6-311G** level of theory, using Monte Carlo and molecular dynamics [141]. The authors used the optimized configurations of neutral and monoprotonated coumaric acid, ferulic acid, syringic acid, vanillic acid, juglone, and myricetin species (Table 4). All these species were found to be capable of being adsorbed on a Fe(110) surface due to their large negative molecule-surface adsorption energies $\left(E_{a d s}\right)$. Moreover, the configurations observed on the adsorbed molecules showed that aromatic rings and heteroatoms were the most likely to be adsorbed on the metal surface, explained through donor-acceptor interactions [164-166]. HOMOs and LUMOs obtained by DFT calculations confirmed these assumptions, since HOMOs are mostly localized on oxygen heteroatoms and aromatic rings, whereas LUMOs are mostly localized on hydroxyl and carbonyl groups. According to the fraction of electrons transferred $(\Delta N)$, neutral molecules tended to donate electrons to the metal surface, whereas monoprotonated species tended to receive charge.

The Glycyrrhiza glabra aqueous extract was theoretically studied by DFT calculations at the B3LYP/6-31G** level through six major constituents: licochalcone A, licochalcone E, liquiritigenin, 18ß-glycyrrhetinic acid, glycyrrhizin, and glabridin (Table 4) [128]. Moreover, a water solvent was considered due to its self-consistent reaction field (SCRF). Monte Carlo and MD calculations were carried out as well. Aromatic benzene rings, methoxy and carbonyl oxygen centers, and $C=C$ double bonds present in the molecules under study were expected to share their electrons to the empty $d$-orbitals on the iron atoms. Furthermore, species with less-negative HOMO energy were found to give more charges to unfilled $d$-orbitals of surface Fe cations, whereas smaller energy of LUMO denoted the tendency to receive electrons. Small HOMO-LUMO energy gaps found for the selected compounds exhibited their capability to easily share electrons to the metal surface. 
Similarly, a theoretical investigation of Sanaei and coworkers regarding the Rosa canina aqueous extract was carried out by DFT, at the B3LYP/6-311G*/SCRF level of theory; MC; and molecular dynamics [146]. Four molecules were studied to deepen into the adsorption mechanism of this extract: ascorbic acid, marein, pectin, and tannin (Table 4). Neutral and monoprotonated species were studied. The authors found that the protonation changed HOMO spatially, affecting the active sites responsible for the adsorption on the metallic surface [146]. Conversely, LUMO remained quite similar for neutral and protonated species. The corrosion inhibitor molecules tended to be adsorbed by hydroxyl, carbonyl, and substituted benzene rings. The authors concluded that the corrosion inhibitor compounds were adsorbed by electron transfer interactions.

Saxena et al. studied the Saraca ashoka extract as a corrosion inhibitor by modeling the epicatechin molecule through DFT calculations (Table 4) [131]. On the basis of global parameters, such as HOMO, LUMO, and $\Delta \mathrm{N}$, the authors suggested that donor-acceptor interactions were established by $\pi$ electrons of aromatic ring and vacant $d$-orbitals of surface iron atoms. Unshared electron pairs of heteroatoms and vacant $d$-orbitals on iron were possible as well.

Four compounds were chosen by Akbarzadeh and coworkers to study the corrosion inhibition properties of the Tamarindus indiaca extract: apigenin, naringenin, eriodyctoyl, and taxifolin (Table 4) [147]. These constituents were modeled by means of DFT, at the B3LYP/6-311G**/Lanl2DZ/SCRF level; MC; and MD approaches. The authors found that $\mathrm{Zn}$-apigenin and $\mathrm{Zn}$-taxifolin complexes tended to be adsorbed by flat orientation on the metal surface. Electron-rich regions, around hydroxyl and 6-membered cycles, and $C=C$ bonds were adsorbed on the iron surface [147].

Similarly, nanocarriers based on a graphene oxide nanoplatform with Tamarindus indiaca extract were studied through theoretical approaches [132]. Naringenin, apigenin, eriodictyol, and taxifolin molecules and their zinc(II) cation complexes with GO were studied by dispersion-corrected DFT (DFT-D) (Table 4). The DFT-D level of theory chosen was PBE/DNP. Complexes tended to form $\pi-\pi$ interactions and H-bonds among organic molecules and GO layers.

Lastly, the aqueous extract of Ziziphora was investigated through DFT, MC, and MD methods. Acacetin, chrysin, and thymonin adopted parallel configurations on the metal surface, leading to a maximized contact area (Table 4). Neutral and monoprotonated species were studied. Electron-rich regions (heterocyclic rings and heteroatoms) were found to be able to donate lone pairs and $\pi$ electrons to the empty $d$-orbitals on iron atoms. MD simulations in liquid phase obtained binding energies following the order thymonin $>$ acacetin $>$ chrysin. Authors proposed the iron surface charges positively in $\mathrm{HCl}$ solution, and thus the chloride ions with negative charge could be adsorbed on the surface. The protonated forms of the Ziziphora leaf extract molecules, which carry a net positive electronic charge, can electrostatically interact with adsorbed chloride ions.

\section{Plant-Based Corrosion Inhibitors in Other Metals}

The Commiphora myrrha extract, with methanol as extraction solvent, was tested by Al-Nami and Fouda in copper in a $2 \mathrm{M} \mathrm{HNO}_{3}$ solution [167]. Weight loss, potentiodynamic polarization, electrochemical frequency (EFM), and electrochemical impedance spectroscopy were used to deepen into the corrosion inhibition properties. WL, EIS, and EFM showed that the inhibition efficiency increased as the inhibitor concentration increased, up to $91.8 \%$ at $300 \mathrm{ppm}$ concentration (Table 5). FT-IR, AFM, and SEM techniques were used to confirm the formation of the protective layer formed on the copper surface. PP curves showed that the extract behaves as a mixed-type inhibitor. Caryophyllene and 1,4-methanoazulene were found to be the major inhibitor components of Commiphora myrrha extract. The Langmuir adsorption isotherm was found to be the most suitable form. 
Table 5. Basic information and parameters obtained with several plant extracts evaluated as corrosion inhibitors in copper and aluminum: plant, extraction solvent, metal and corrosive medium used for corrosion inhibition performance tests, temperature and concentration $C$ ranges tested, maximum inhibition efficiency obtained $\left(\eta_{\max }\right)$, and characterizations reported are included.

\begin{tabular}{ccccccccc}
\hline Plant & $\begin{array}{c}\text { Extraction } \\
\text { Solvent }\end{array}$ & Metal & $\begin{array}{c}\text { Corrosion } \\
\text { Medium }\end{array}$ & $\eta_{\max }(\%)$ & Temp (K) & $\mathrm{C}$ & Characterization & Reference \\
\hline Borassus flabellifer & $\begin{array}{c}\text { Water, } \\
\text { methanol }\end{array}$ & $\mathrm{Al}$ & $1 \mathrm{M} \mathrm{H}_{2} \mathrm{SO}_{4}$ & 66.8 & $303-333$ & $0.1-0.4 \mathrm{~g} / \mathrm{L}$ & EIS, SEM & [11] \\
\hline Commiphora myrrha & Methanol & $\mathrm{Cu}$ & $2 \mathrm{M} \mathrm{HNO}_{3}$ & 91 & $298.15-318.15$ & $50-300 \mathrm{ppm}$ & $\begin{array}{c}\text { EIS, AFM, FT-IR, } \\
\text { SEM, PP, WL }\end{array}$ & {$[167]$} \\
\hline Equisetum arvense & Methanol & $\mathrm{Cu}$ & Seawater & 87.5 & 300 & $250-1000 \mathrm{ppm}$ & $\begin{array}{c}\text { EIS, FT-IR, PP, } \\
\text { GC-MS }\end{array}$ & {$[168]$} \\
\hline Hemerocallis fulva & Methanol & $\mathrm{Al}$ & $1 \mathrm{M} \mathrm{H}_{2} \mathrm{SO}_{4}$ & 89 & $303-333$ & $200-600 \mathrm{ppm}$ & $\begin{array}{c}\text { WL, PP, } \\
\text { SEM-EDS, AFM }\end{array}$ & {$[169]$} \\
\hline
\end{tabular}

Similarly, the corrosion inhibition properties of Equisetum arvense extract on copper substrate in seawater as corrosive medium was studied by Esquivel-Lopez et al. [168]. They found, by means of EIS tests, a maximum inhibition efficiency of about $87.5 \%$ (Table 5). Results were confirmed by LPR technique. Gas chromatography coupled to mass spectrometry and FT-IR were used to reveal the chemical structure of the extract constituents: 9,12,15-octadecatrienoic acid, methyl ester, hexadecanoic acid, 2,3-dihydro-2,5-dihydroxy-6-methyl-4H-pyran-4one, sitosterol, campesterol, 5-hydroxymethyl-2-furancarboxaldehyde, hexadecanoic acid, and 9,12-octadecadienoic acid. Morphological characterization, with and without corrosion inhibitor, was obtained by SEM micrographs.

Corrosion inhibition on aluminum, in a $1 \mathrm{M} \mathrm{H}_{2} \mathrm{SO}_{4}$ solution, was tested with the Hemerocallis fulva extract obtained with methanol as solvent [169]. Results obtained at different concentrations and temperatures exhibit a maximum inhibition efficiency of about $89 \%$ at $600 \mathrm{ppm}$ and $303 \pm 1 \mathrm{~K}$ (Table 5). The adsorption of inhibitor molecules on the metal surface followed the Langmuir isotherm and agreed with physisorption. PP curves agreed with mixed inhibition. P-coumaric acid, ferulic acid, $\mathrm{m}$-coumaric acid, o-coumaric acid, kaempferol, gallic acid, protocatechuic acid, syringic acid, gentisic acid, and quercetin were determined by ultra-high-performance liquid chromatography as the major components of Hemerocallis fulva extract. SEM/EDS measurements and AFM were used to study the morphology of the aluminum surface and to confirm the formation of the protective layer.

Moreover, corrosion inhibition in aluminum in a $1 \mathrm{M} \mathrm{H}_{2} \mathrm{SO}_{4}$ corrosive medium was studied using water and methanol extracts of Borassus flabellifer [11]. PP and EIS revealed that the corrosion inhibition efficiency increased as the inhibitor concentration increased. According to PP measurements, maximum inhibition efficiencies of $66.88 \%$ and $51.85 \%$ were obtained with methanol and water extracts at $0.40 \mathrm{~g} / \mathrm{L}$ concentrations, respectively (Table 5). Moreover, the mixed-type inhibition performance of both extracts was determined by PP measurements. SEM micrographs confirmed the formation of a protective film on top of aluminum surface as well as the reduction of the damage caused by corrosion.

All the studies described above highlight an alternative to the current challenges in the industry, for instance, the way in which to obtain novel organic compounds obtained from renewable sources that are being non-toxic and biodegradable [170]. Reports described in this work include natural extracts proven to act as green corrosion inhibitors on different metals. These are obtained from seeds, fruits, leaves, flowers, etc. Notably, corrosion was slowed down, achieving high corrosion inhibition efficiencies up to values around $90 \%$ (Table 3). These plant extracts contained phytochemicals, particularly heterocycles, that inhibit the corrosion in an efficient manner. Thus, synthetic organic chemistry groups can be inspired by the compounds compiled here to produce similar corrosion inhibitors. Moreover, large-scale industrial production requires additional processes beyond the parameters shown in this manuscript, opening the door to further experiments and characterizations on plant extracts [170]. Lastly, isolated organic molecules, responsible for the corrosion inhibition effect, must be studied alongside the consideration of other variables, such as inhibitor concentration, 
temperature, and release flux. This is all in order to fulfill the norms established for their use in petrochemical, maritime, food, and other industries, such as the reference standard norm (NRF-005PEMEX-2009) in México [171]. However, one of the drawbacks when evaluating the inhibition efficiency is related to the diversity in chemical composition that present pickles in the field (different salinity). In this way, the use of NACE 1D182 brine is the most suitable, due to its chemical composition, with high content of salts compared to other brines, for example, the one indicated in NACE 1D196 and ASTM D1141.

\section{Conclusions}

The most recent reports on plant extracts that have been evaluated to act as corrosion inhibitors on metal surfaces, mostly in steel, are briefly reviewed. Many variables can be explored to evaluate a plant extract as corrosion inhibitor: concentration, extraction solvent, temperature, and immersion time. The effectiveness of a corrosion inhibitor must be evaluated by at least two electrochemical techniques such as PP, EIS, WL, and others. Constituent compounds of the plant extracts are commonly adsorbed on the metal and are described by the Langmuir model: through physisorption, chemisorption, or mixed mechanisms. Physisorption is usually explained by the interactions among the polar regions of the inhibitor molecules on the metal surface. Chemisorption is due to electron sharing between the inhibitor molecule, from electron-rich regions and heteroatoms, and the metal surface. Phytochemicals obtained from extracts, mostly heterocyclic compounds, are suitable for robust interaction with the metal surface and consequently for the inhibition of corrosion. Theoretical studies, within density functional theory and molecular dynamics theoretical frameworks, are mostly used to elucidate the adsorption mechanism and inhibitor-metal interactions. Lastly, some new contributions on copper and aluminum corrosion inhibition by plant extracts have been discussed as well. Plant extracts obtained corrosion inhibition efficiencies above $60 \%$, most of them around $80-90 \%$. The most important challenge is to have an extract or to isolate the main component that has an inhibition efficiency greater than $90 \%$ according to the norm NRF-005-PEMEX- 2009. This compilation can be used as inspiration for research groups to obtain novel organic corrosion inhibitors. Moreover, specific compounds can be isolated and studied, with the aim of producing them in large quantities required for the industry.

Author Contributions: A.M. and A.E.V.: Conceptualization, investigation, formal analysis, writing-original draft, writing-review and editing. All authors have read and agreed to the published version of the manuscript.

Funding: The APC was funded by Tecnológico de Monterrey through grants for scientific papers publication fund.

Acknowledgments: A.M. thanks Tecnológico de Monterrey strategic research group on nanomaterials. Also, A.M. thanks D.S. Tagle-Miralrio for her support with diagrams and figures. Moreover, A.M. thanks J. Muñoz-Villota for her invaluable support during the writing of this manuscript and during the pandemic. A.E.V. and A.M. wish to acknowledge the SNI for the distinction of their membership and the stipend received.

Conflicts of Interest: The authors declare no conflict of interest.

$\begin{array}{ll}\text { Abbreviations } & \\ \text { Atomic force microscope } & \text { AFM } \\ \text { Density functional theory } & \text { DFT } \\ \text { Dispersion-corrected density functional theory } & \text { DFT-D } \\ \text { Electrochemical frequency } & \text { EFM } \\ \text { Electrochemical impedance spectroscopy } & \text { EIS } \\ \text { Electrostatic potential } & \text { ESP } \\ \text { Energy-dispersive X-ray spectroscopy } & \text { EDS } \\ \text { Fourier transform infrared spectroscopy } & \text { FT-IR } \\ \text { Gas chromatography mass spectrometry } & \text { GC-MS } \\ \text { Graphene oxide } & \text { GO } \\ \text { Hydrochloric acid } & \text { HCl }\end{array}$




$\begin{array}{ll}\text { Highest occupied molecular orbital } & \text { HOMO } \\ \text { Linear polarization resistance } & \text { LPR } \\ \text { Lowest unoccupied molecular orbital } & \text { LUMO } \\ \text { Molecular dynamics } & \text { MD } \\ \text { Monte Carlo } & \text { MC } \\ \text { Potentiodynamic polarization } & \text { PP } \\ \text { Proton-nuclear magnetic resonance } & { }^{1} \mathrm{H} \text { NMR } \\ \text { Scanning electron microscope } & \text { SEM } \\ \text { Self-consistent reaction field } & \text { SCRF } \\ \text { Tamarindus indiaca extract } & \text { Ti.E/TAM } \\ \text { Ultraviolet-visible spectroscopy } & \text { UV-VIS } \\ \text { Weight loss method } & \text { WL } \\ \text { X-ray photoelectron spectroscopy } & \text { XPS } \\ \text { Zinc nitrate } & \text { ZS }\end{array}$

\section{References}

1. Parthipan, P.; Elumalai, P.; Narenkumar, J.; Machuca, L.L.; Murugan, K.; Karthikeyan, O.P.; Rajasekar, A. Allium sativum (garlic extract) as a green corrosion inhibitor with biocidal properties for the control of MIC in carbon steel and stainless steel in oilfield environments. Int. Biodeterior. Biodegrad. 2018, 132, 66-73. [CrossRef]

2. Loto, R.T.; Olowoyo, O. Synergistic effect of sage and jojoba oil extracts on the corrosion inhibition of mild steel in dilute acid solution. Procedia Manuf. 2019, 35, 310-314. [CrossRef]

3. Anupama, K.K.; Ramya, K.; Joseph, A. Electrochemical measurements and theoretical calculations on the inhibitive interaction of Plectranthus amboinicus leaf extract with mild steel in hydrochloric acid. Measurement 2017, 95, 297-305. [CrossRef]

4. Verma, C.; Ebenso, E.E.; Bahadur, I.; Quraishi, M.A. An overview on plant extracts as environmental sustainable and green corrosion inhibitors for metals and alloys in aggressive corrosive media. J. Mol. Liq. 2018, 266, 577-590. [CrossRef]

5. Zhu, Y.; Wang, L.; Behnamian, Y.; Song, S.; Wang, R.; Gao, Z.; Hu, W.; Xia, D.-H. Metal pitting corrosion characterized by scanning acoustic microscopy and binary image processing. Corros. Sci. 2020, 170, 108685. [CrossRef]

6. Mai, W.; Soghrati, S.; Buchheit, R.G. A phase field model for simulating the pitting corrosion. Corros. Sci. 2016, 110, 157-166. [CrossRef]

7. Kıcır, N.; Tansuğ, G.; Erbil, M.; Tüken, T. Investigation of ammonium (2,4-dimethylphenyl)-dithiocarbamate as a new, effective corrosion inhibitor for mild steel. Corros. Sci. 2016, 105, 88-99. [CrossRef]

8. Singh, P.; Srivastava, V.; Quraishi, M.A. Novel quinoline derivatives as green corrosion inhibitors for mild steel in acidic medium: Electrochemical, SEM, AFM, and XPS studies. J. Mol. Liq. 2016, 216, 164-173. [CrossRef]

9. El Ibrahimi, B.; Jmiai, A.; Bazzi, L.; El Issami, S. Amino acids and their derivatives as corrosion inhibitors for metals and alloys. Arab. J. Chem. 2020, 13, 740-771. [CrossRef]

10. Ladan, M.; Basirun, W.J.; Kazi, S.N.; Rahman, F.A. Corrosion protection of AISI 1018 steel using Co-doped $\mathrm{TiO}_{2}$ /polypyrrole nanocomposites in 3.5\% NaCl solution. Mater. Chem. Phys. 2017, 192, 361-373. [CrossRef]

11. Nathiya, R.S.; Perumal, S.; Murugesan, V.; Raj, V. Evaluation of extracts of Borassus flabellifer dust as green inhibitors for aluminium corrosion in acidic media. Mater. Sci. Semicond. Process. 2019, 104, 104674. [CrossRef]

12. Laabaissi, T.; Benhiba, F.; Missioui, M.; Rouifi, Z.; Rbaa, M.; Oudda, H.; Ramli, Y.; Guenbour, A.; Warad, I.; Zarrouk, A. Coupling of chemical, electrochemical and theoretical approach to study the corrosion inhibition of mild steel by new quinoxaline compounds in $1 \mathrm{M} \mathrm{HCl}$. Heliyon 2020, 6, e03939. [CrossRef] [PubMed]

13. El Aoufir, Y.; Aslam, R.; Lazrak, F.; Marzouki, R.; Kaya, S.; Skal, S.; Ghanimi, A.; Ali, I.H.; Guenbour, A.; Lgaz, H.; et al. The effect of the alkyl chain length on corrosion inhibition performances of 1,2,4-triazole-based compounds for mild steel in $1.0 \mathrm{M} \mathrm{HCl}$ : Insights from experimental and theoretical studies. J. Mol. Liq. 2020, 303, 112631. [CrossRef] 
14. Hashim, N.Z.N.; Anouar, E.H.; Kassim, K.; Zaki, H.M.; Alharthi, A.I.; Embong, Z. XPS and DFT investigations of corrosion inhibition of substituted benzylidene Schiff bases on mild steel in hydrochloric acid. Appl. Surf. Sci. 2019, 476, 861-877. [CrossRef]

15. Gao, M.; Zhang, J.; Liu, Q.; Li, J.; Zhang, R.; Chen, G. Effect of the alkyl chain of quaternary ammonium cationic surfactants on corrosion inhibition in hydrochloric acid solution. Comptes Rendus Chim. 2019, 22, 355-362. [CrossRef]

16. Shahabi, S.; Hamidi, S.; Ghasemi, J.B.; Norouzi, P.; Shakeri, A. Synthesis, experimental, quantum chemical and molecular dynamics study of carbon steel corrosion inhibition effect of two Schiff bases in $\mathrm{HCl}$ solution. J. Mol. Liq. 2019, 285, 626-639. [CrossRef]

17. Talebian, M.; Raeissi, K.; Atapour, M.; Fernández-Pérez, B.M.; Betancor-Abreu, A.; Llorente, I.; Fajardo, S.; Salarvand, Z.; Meghdadi, S.; Amirnasr, M.; et al. Pitting corrosion inhibition of 304 stainless steel in $\mathrm{NaCl}$ solution by three newly synthesized carboxylic Schiff bases. Corros. Sci. 2019, 160, 108130. [CrossRef]

18. Devikala, S.; Kamaraj, P.; Arthanareeswari, M.; Patel, M.B. Green corrosion inhibition of mild steel by aqueous Allium sativum extract in 3.5\% NaCl. Mater. Today Proc. 2019, 14, 580-589. [CrossRef]

19. Huang, H.; Guo, X. The relationship between the inhibition performances of three benzo derivatives and their structures on the corrosion of copper in $3.5 \mathrm{wt} \% \mathrm{NaCl}$ solution. Colloids Surf. Physicochem. Eng. Asp. 2020, 598, 124809. [CrossRef]

20. Othman, N.K.; Yahya, S.; Ismail, M.C. Corrosion inhibition of steel in $3.5 \% \mathrm{NaCl}$ by rice straw extract. J. Ind. Eng. Chem. 2019, 70, 299-310. [CrossRef]

21. Singh, A.; Lin, Y.; Ebenso, E.E.; Liu, W.; Pan, J.; Huang, B. Gingko biloba fruit extract as an eco-friendly corrosion inhibitor for $\mathrm{J} 55$ steel in $\mathrm{CO}_{2}$ saturated 3.5\% NaCl solution. J. Ind. Eng. Chem. 2015, 24, 219-228. [CrossRef]

22. Shabani-Nooshabadi, M.; Ghandchi, M.S. Santolina chamaecyparissus extract as a natural source inhibitor for 304 stainless steel corrosion in 3.5\% NaCl. J. Ind. Eng. Chem. 2015, 31, 231-237. [CrossRef]

23. Guruprasad, A.M.; Sachin, H.P.; Swetha, G.A.; Prasanna, B.M. Corrosion inhibition of zinc in $0.1 \mathrm{M}$ hydrochloric acid medium with clotrimazole: Experimental, theoretical and quantum studies. Surf. Interfaces 2020, 19, 100478. [CrossRef]

24. Padash, R.; Sajadi, G.S.; Jafari, A.H.; Jamalizadeh, E.; Rad, A.S. Corrosion control of aluminum in the solutions of $\mathrm{NaCl}, \mathrm{HCl}$ and $\mathrm{NaOH}$ using 2,6-dimethylpyridine inhibitor: Experimental and DFT insights. Mater. Chem. Phys. 2020, 244, 122681. [CrossRef]

25. Al Hasan, N.H.J.; Alaradi, H.J.; Al Mansor, Z.A.K.; Al Shadood, A.H.J. The dual effect of stem extract of Brahmi (Bacopamonnieri) and Henna as a green corrosion inhibitor for low carbon steel in $0.5 \mathrm{M} \mathrm{NaOH}$ solution. Case Stud. Constr. Mater. 2019, 11, e00300. [CrossRef]

26. Natarajan, S.; Kumaresh Babu, S.P. Corrosion and its inhibition in SA213-T22 TIG weldments used in power plants under neutral and alkaline environments. Mater. Sci. Eng. A 2006, 432, 47-51. [CrossRef]

27. Li, X.; Deng, S.; Xie, X.; Du, G. Synergistic inhibition effect of 5-aminotetrazole and 4,6-dihydroxypyrimidine on the corrosion of cold rolled steel in $\mathrm{H}_{3} \mathrm{PO}_{4}$ solution. Mater. Chem. Phys. 2016, 181, 33-46. [CrossRef]

28. Li, X.; Deng, S.; Fu, H.; Xie, X. Synergistic inhibition effects of bamboo leaf extract/major components and iodide ion on the corrosion of steel in $\mathrm{H}_{3} \mathrm{PO}_{4}$ solution. Corros. Sci. 2014, 78, 29-42. [CrossRef]

29. Ismail, A.S.; Farag, A.A. Experimental, theoretical and simulation studies of extracted crab waste protein as a green polymer inhibitor for carbon steel corrosion in $2 \mathrm{M} \mathrm{H}_{3} \mathrm{PO}_{4}$. Surf. Interfaces 2020, 19, 100483. [CrossRef]

30. Mahalakshmi, D.; Hemapriya, V.; Subramaniam, E.P.; Chitra, S. Synergistic effect of antibiotics on the inhibition property of aminothiazolyl coumarin for corrosion of mild steel in $0.5 \mathrm{M} \mathrm{H}_{2} \mathrm{SO}_{4}$. J. Mol. Liq. 2019, 284, 316-327. [CrossRef]

31. Bagga, M.K.; Gadi, R.; Yadav, O.S.; Kumar, R.; Chopra, R.; Singh, G. Investigation of phytochemical components and corrosion inhibition property of Ficus racemosa stem extract on mild steel in $\mathrm{H}_{2} \mathrm{SO}_{4}$ medium. J. Environ. Chem. Eng. 2016, 4, 4699-4707. [CrossRef]

32. Jiang, S.; Chai, F.; Su, H.; Yang, C. Influence of chromium on the flow-accelerated corrosion behavior of low alloy steels in 3.5\% NaCl solution. Corros. Sci. 2017, 123, 217-227. [CrossRef]

33. Dohare, P.; Chauhan, D.S.; Sorour, A.A.; Quraishi, M.A. DFT and experimental studies on the inhibition potentials of expired Tramadol drug on mild steel corrosion in hydrochloric acid. Mater. Discov. 2017, 9, 30-41. [CrossRef] 
34. El-Haddad, M.N.; Fouda, A.S.; Hassan, A.F. Data from Chemical, electrochemical and quantum chemical studies for interaction between Cephapirin drug as an eco-friendly corrosion inhibitor and carbon steel surface in acidic medium. Chem. Data Collect. 2019, 22, 100251. [CrossRef]

35. Gholamhosseinzadeh, M.R.; Aghaie, H.; Zandi, M.S.; Giahi, M. Rosuvastatin drug as a green and effective inhibitor for corrosion of mild steel in $\mathrm{HCl}$ and $\mathrm{H}_{2} \mathrm{SO}_{4}$ solutions. J. Mater. Res. Technol. 2019, 8, 5314-5324. [CrossRef]

36. Farahati, R.; Mousavi-Khoshdel, S.M.; Ghaffarinejad, A.; Behzadi, H. Experimental and computational study of penicillamine drug and cysteine as water-soluble green corrosion inhibitors of mild steel. Prog. Org. Coat. 2020, 142, 105567. [CrossRef]

37. Espinoza-Vázquez, A.; Rodríguez-Gómez, F.J.; Negrón-Silva, G.E.; González-Olvera, R.; Ángeles-Beltrán, D.; Palomar-Pardavé, M.; Miralrio, A.; Castro, M. Fluconazole and fragments as corrosion inhibitors of API 5L X52 steel immersed in $1 \mathrm{M} \mathrm{HCl}$. Corros. Sci. 2020, 174, 108853. [CrossRef]

38. Zhao, Q.; Guo, J.; Cui, G.; Han, T.; Wu, Y. Chitosan derivatives as green corrosion inhibitors for P110 steel in a carbon dioxide environment. Colloids Surf. B Biointerfaces 2020, 194, 111150. [CrossRef]

39. Machado Fernandes, C.; Pina, V.G.S.S.; Alvarez, L.X.; de Albuquerque, A.C.F.; dos Santos Júnior, F.M.; Barrios, A.M.; Velasco, J.A.C.; Ponzio, E.A. Use of a theoretical prediction method and quantum chemical calculations for the design, synthesis and experimental evaluation of three green corrosion inhibitors for mild steel. Colloids Surf. Physicochem. Eng. Asp. 2020, 599, 124857. [CrossRef]

40. Munis, A.; Zhao, T.; Zheng, M.; Rehman, A.U.; Wang, F. A newly synthesized green corrosion inhibitor imidazoline derivative for carbon steel in $7.5 \% \mathrm{NH}_{4} \mathrm{Cl}$ solution. Sustain. Chem. Pharm. 2020, 16, 100258. [CrossRef]

41. Verma, C.; Ebenso, E.E.; Quraishi, M.A. Ionic liquids as green and sustainable corrosion inhibitors for metals and alloys: An overview. J. Mol. Liq. 2017, 233, 403-414. [CrossRef]

42. Olawale, O.; Bello, J.O.; Ogunsemi, B.T.; Uchella, U.C.; Oluyori, A.P.; Oladejo, N.K. Optimization of chicken nail extracts as corrosion inhibitor on mild steel in $2 \mathrm{M} \mathrm{H}_{2} \mathrm{SO}_{4}$. Heliyon 2019, 5, e02821. [CrossRef] [PubMed]

43. Pradeep Kumar, C.B.; Mohana, K.N. Phytochemical screening and corrosion inhibitive behavior of Pterolobium hexapetalum and Celosia argentea plant extracts on mild steel in industrial water medium. Egypt. J. Pet. 2014, 23, 201-211. [CrossRef]

44. Marsoul, A.; Ijjaali, M.; Elhajjaji, F.; Taleb, M.; Salim, R.; Boukir, A. Phytochemical screening, total phenolic and flavonoid methanolic extract of pomegranate bark (Punica granatum L): Evaluation of the inhibitory effect in acidic medium $1 \mathrm{M} \mathrm{HCl}$. Mater. Today Proc. 2020, S2214785320328170. [CrossRef]

45. Sedik, A.; Lerari, D.; Salci, A.; Athmani, S.; Bachari, K.; Gecibesler, İ.H.; Solmaz, R. Dardagan Fruit extract as eco-friendly corrosion inhibitor for mild steel in $1 \mathrm{M} \mathrm{HCl}$ : Electrochemical and surface morphological studies. J. Taiwan Inst. Chem. Eng. 2020, 107, 189-200. [CrossRef]

46. Dehghani, A.; Bahlakeh, G.; Ramezanzadeh, B.; Ramezanzadeh, M. Potential of Borage flower aqueous extract as an environmentally sustainable corrosion inhibitor for acid corrosion of mild steel: Electrochemical and theoretical studies. J. Mol. Liq. 2019, 277, 895-911. [CrossRef]

47. Chaubey, N.; Singh, V.K.; Quraishi, M.A. Papaya peel extract as potential corrosion inhibitor for Aluminium alloy in $1 \mathrm{M} \mathrm{HCl}$ : Electrochemical and quantum chemical study. Ain Shams Eng. J. 2018, 9, 1131-1140. [CrossRef]

48. Jokar, M.; Farahani, T.S.; Ramezanzadeh, B. Electrochemical and surface characterizations of morus alba pendula leaves extract (MAPLE) as a green corrosion inhibitor for steel in $1 \mathrm{M} \mathrm{HCl}$. J. Taiwan Inst. Chem. Eng. 2016, 63, 436-452. [CrossRef]

49. Dehghani, A.; Bahlakeh, G.; Ramezanzadeh, B.; Ramezanzadeh, M. Experimental complemented with microscopic (electronic/atomic)-level modeling explorations of Laurus nobilis extract as green inhibitor for carbon steel in acidic solution. J. Ind. Eng. Chem. 2020, 84, 52-71. [CrossRef]

50. Handa, S. An overview of extraction techniques for medicinal and aromatic plants. Extr. Technol. Med. Aromat. Plants 2008, 1, 50-52.

51. Zhang, Q.-W.; Lin, L.-G.; Ye, W.-C. Techniques for extraction and isolation of natural products: A comprehensive review. Chin. Med. 2018, 13, 20. [CrossRef] [PubMed]

52. Azmir, J.; Zaidul, I.S.M.; Rahman, M.M.; Sharif, K.M.; Mohamed, A.; Sahena, F.; Jahurul, M.H.A.; Ghafoor, K.; Norulaini, N.A.N.; Omar, A.K.M. Techniques for extraction of bioactive compounds from plant materials: A review. J. Food Eng. 2013, 117, 426-436. [CrossRef] 
53. Azwanida, N.N. A Review on the Extraction Methods Use in Medicinal Plants, Principle, Strength and Limitation. Med. Aromat. Plants 2015, 4. [CrossRef]

54. Pham, H.; Nguyen, V.; Vuong, Q.; Bowyer, M.; Scarlett, C. Effect of Extraction Solvents and Drying Methods on the Physicochemical and Antioxidant Properties of Helicteres hirsuta Lour. Leaves. Technologies 2015, 3, 285-301. [CrossRef]

55. Neffati, N.; Aloui, Z.; Karoui, H.; Guizani, I.; Boussaid, M.; Zaouali, Y. Phytochemical composition and antioxidant activity of medicinal plants collected from the Tunisian flora. Nat. Prod. Res. 2017, 31, 1583-1588. [CrossRef]

56. Seal, T. Quantitative HPLC analysis of phenolic acids, flavonoids and ascorbic acid in four different solvent extracts of two wild edible leaves, Sonchus arvensis and Oenanthe linearis of North-Eastern region in India. J. Appl. Pharm. Sci. 2016, 157-166. [CrossRef]

57. Sharghi, H.; Khalifeh, R.; Doroodmand, M.M. Copper Nanoparticles on Charcoal for Multicomponent Catalytic Synthesis of 1,2,3-Triazole Derivatives from Benzyl Halides or Alkyl Halides, Terminal Alkynes and Sodium Azide in Water as a "Green" Solvent. Adv. Synth. Catal. 2009, 351, 207-218. [CrossRef]

58. Varma, R.S. Greener and Sustainable Trends in Synthesis of Organics and Nanomaterials. ACS Sustain. Chem. Eng. 2016, 4, 5866-5878. [CrossRef]

59. Duan, H.; Wang, D.; Li, Y. Green chemistry for nanoparticle synthesis. Chem. Soc. Rev. 2015, 44, 5778-5792. [CrossRef]

60. Nóbrega, E.M.; Oliveira, E.L.; Genovese, M.I.; Correia, R.T.P. The Impact of Hot Air Drying on the Physical-Chemical Characteristics, Bioactive Compounds and Antioxidant Activity of Acerola (Malphigia emarginata) Residue: Hot Air Dried Acerola Residue. J. Food Process. Preserv. 2015, 39, 131-141. [CrossRef]

61. Marchante, L.; Gómez Alonso, S.; Alañón, M.E.; Pérez-Coello, M.S.; Díaz-Maroto, M.C. Natural extracts from fresh and oven-dried winemaking by-products as valuable source of antioxidant compounds. Food Sci. Nutr. 2018, 6, 1564-1574. [CrossRef] [PubMed]

62. Li, Y.; Hong, Y.; Han, Y.; Wang, Y.; Xia, L. Chemical characterization and antioxidant activities comparison in fresh, dried, stir-frying and carbonized ginger. J. Chromatogr. B 2016, 1011, 223-232. [CrossRef]

63. Scavo, A.; Pandino, G.; Restuccia, A.; Mauromicale, G. Leaf extracts of cultivated cardoon as potential bioherbicide. Sci. Hortic. 2020, 261, 109024. [CrossRef]

64. Mo, S.; Luo, H.-Q.; Li, N.-B. Plant extracts as "green" corrosion inhibitors for steel in sulphuric acid. Chem. Pap. 2016, 70, 1131-1143. [CrossRef]

65. Esmailzadeh, S.; Aliofkhazraei, M.; Sarlak, H. Interpretation of Cyclic Potentiodynamic Polarization Test Results for Study of Corrosion Behavior of Metals: A Review. Prot. Met. Phys. Chem. Surf. 2018, 54, 976-989. [CrossRef]

66. Vaamonde, A.J.V.; de Damborenea, J.J.; González, J.J.D. Ciencia e Ingeniería de la Superficie de los Materiales Metálicos; Editorial CSIC-CSIC Press: Madrid, Spain, 2000; Volume 31, ISBN 84-00-07920-5.

67. Orazem, M.E.; Tribollet, B. Electrochemical Impedance Spectroscopy; John Wiley \& Sons: Hoboken, NJ, USA, 2017; ISBN 1-118-52739-9.

68. Mansfeld, F. Fundamental aspects of the polarization resistance technique-The early days. J. Solid State Electrochem. 2009, 13, 515-520. [CrossRef]

69. Saxena, A.; Thakur, K.K.; Bhardwaj, N. Electrochemical studies and surface examination of low carbon steel by applying the extract of Musa acuminata. Surf. Interfaces 2020, 18, 100436. [CrossRef]

70. Vengatesh, G.; Sundaravadivelu, M. Non-toxic bisacodyl as an effective corrosion inhibitor for mild steel in $1 \mathrm{M} \mathrm{HCl}$ : Thermodynamic, electrochemical, SEM, EDX, AFM, FT-IR, DFT and molecular dynamics simulation studies. J. Mol. Liq. 2019, 287, 110906. [CrossRef]

71. Haldhar, R.; Prasad, D.; Saxena, A. Armoracia rusticana as sustainable and eco-friendly corrosion inhibitor for mild steel in $0.5 \mathrm{M}$ sulphuric acid: Experimental and theoretical investigations. J. Environ. Chem. Eng. 2018, 6, 5230-5238. [CrossRef]

72. Finšgar, M. Electrochemical, 3D topography, XPS, and ToF-SIMS analyses of 4-methyl-2-phenylimidazole as a corrosion inhibitor for brass. Corros. Sci. 2020, 169, 108632. [CrossRef]

73. Li, X.; Deng, S.; Fu, H. Synergistic inhibition effect of red tetrazolium and uracil on the corrosion of cold rolled steel in $\mathrm{H}_{3} \mathrm{PO}_{4}$ solution: Weight loss, electrochemical, and AFM approaches. Mater. Chem. Phys. 2009, 115, 815-824. [CrossRef] 
74. Haldhar, R.; Prasad, D.; Saxena, A. Myristica fragrans extract as an eco-friendly corrosion inhibitor for mild steel in $0.5 \mathrm{M} \mathrm{H}_{2} \mathrm{SO}_{4}$ solution. J. Environ. Chem. Eng. 2018, 6, 2290-2301. [CrossRef]

75. Singh, A.; Ansari, K.R.; Chauhan, D.S.; Quraishi, M.A.; Kaya, S. Anti-corrosion investigation of pyrimidine derivatives as green and sustainable corrosion inhibitor for N80 steel in highly corrosive environment: Experimental and AFM/XPS study. Sustain. Chem. Pharm. 2020, 16, 100257. [CrossRef]

76. Bouanis, M.; Tourabi, M.; Nyassi, A.; Zarrouk, A.; Jama, C.; Bentiss, F. Corrosion inhibition performance of 2,5-bis(4-dimethylaminophenyl)-1,3,4-oxadiazole for carbon steel in $\mathrm{HCl}$ solution: Gravimetric, electrochemical and XPS studies. Appl. Surf. Sci. 2016, 389, 952-966. [CrossRef]

77. Corrales Luna, M.; Le Manh, T.; Cabrera Sierra, R.; Medina Flores, J.V.; Lartundo Rojas, L.; Arce Estrada, E.M. Study of corrosion behavior of API 5L X52 steel in sulfuric acid in the presence of ionic liquid 1-ethyl 3-methylimidazolium thiocyanate as corrosion inhibitor. J. Mol. Liq. 2019, 289, 111106. [CrossRef]

78. Zarrok, H.; Zarrouk, A.; Hammouti, B.; Salghi, R.; Jama, C.; Bentiss, F. Corrosion control of carbon steel in phosphoric acid by purpald-Weight loss, electrochemical and XPS studies. Corros. Sci. 2012, 64, $243-252$. [CrossRef]

79. Brycki, B.E.; Kowalczyk, I.H.; Szulc, A.; Kaczerewska, O.; Pakiet, M. Organic Corrosion Inhibitors. In Corrosion Inhibitors, Principles and Recent Applications; Aliofkhazraei, M., Ed.; InTech: London, UK, 2018; ISBN 978-953-51-3917-1.

80. Richardson, J.A. Management of Corrosion in the Petrochemical and Chemical Industries. In Shreir's Corrosion; Elsevier: Amsterdam, The Netherlands, 2010; pp. 3207-3229. ISBN 978-0-444-52787-5.

81. Papavinasam, S. Corrosion Inhibitors. In Uhlig's Corrosion Handbook; Revie, R.W., Ed.; John Wiley \& Sons Inc.: Hoboken, NJ, USA, 2011; pp. 1021-1032. ISBN 978-0-470-87286-4.

82. Pradipta, I.; Kong, D.; Tan, J.B.L. Natural organic antioxidants from green tea inhibit corrosion of steel reinforcing bars embedded in mortar. Constr. Build. Mater. 2019, 227, 117058. [CrossRef]

83. Loto, R.T.; Loto, C.A. Data on the comparative evaluation of the corrosion inhibition of vanillin and vanillin admixed with rosmarinus officinalis on mild steel in dilute acid media. Chem. Data Collect. 2019, 24, 100290. [CrossRef]

84. Alvarez, P.E.; Fiori-Bimbi, M.V.; Neske, A.; Brandán, S.A.; Gervasi, C.A. Rollinia occidentalis extract as green corrosion inhibitor for carbon steel in $\mathrm{HCl}$ solution. J. Ind. Eng. Chem. 2018, 58, 92-99. [CrossRef]

85. Zhang, W.; Li, H.-J.; Chen, L.; Zhang, S.; Ma, Y.; Ye, C.; Zhou, Y.; Pang, B.; Wu, Y.-C. Fructan from Polygonatum cyrtonema Hua as an eco-friendly corrosion inhibitor for mild steel in $\mathrm{HCl}$ media. Carbohydr. Polym. 2020, 238, 116216. [CrossRef]

86. Hassan, K.H.; Khadom, A.A.; Kurshed, N.H. Citrus aurantium leaves extracts as a sustainable corrosion inhibitor of mild steel in sulfuric acid. S. Afr. J. Chem. Eng. 2016, 22, 1-5. [CrossRef]

87. Chen, S.; Chen, S.; Zhu, B.; Huang, C.; Li, W. Magnolia grandiflora leaves extract as a novel environmentally friendly inhibitor for Q235 steel corrosion in $1 \mathrm{M} \mathrm{HCl}$ : Combining experimental and theoretical researches. J. Mol. Liq. 2020, 113312. [CrossRef]

88. Gao, L.; Peng, S.; Huang, X.; Gong, Z. A combined experimental and theoretical study of papain as a biological eco-friendly inhibitor for copper corrosion in $\mathrm{H}_{2} \mathrm{SO}_{4}$ medium. Appl. Surf. Sci. 2020, 511, 145446. [CrossRef]

89. Anadebe, V.C.; Onukwuli, O.D.; Omotioma, M.; Okafor, N.A. Experimental, theoretical modeling and optimization of inhibition efficiency of pigeon pea leaf extract as anti-corrosion agent of mild steel in acid environment. Mater. Chem. Phys. 2019, 233, 120-132. [CrossRef]

90. Dehghani, A.; Bahlakeh, G.; Ramezanzadeh, B.; Ramezanzadeh, M. A combined experimental and theoretical study of green corrosion inhibition of mild steel in $\mathrm{HCl}$ solution by aqueous Citrullus lanatus fruit (CLF) extract. J. Mol. Liq. 2019, 279, 603-624. [CrossRef]

91. Ramezanzadeh, M.; Bahlakeh, G.; Ramezanzadeh, B. Study of the synergistic effect of Mangifera indica leaves extract and zinc ions on the mild steel corrosion inhibition in simulated seawater: Computational and electrochemical studies. J. Mol. Liq. 2019, 292, 111387. [CrossRef]

92. Pal, S.; Lgaz, H.; Tiwari, P.; Chung, I.-M.; Ji, G.; Prakash, R. Experimental and theoretical investigation of aqueous and methanolic extracts of Prunus dulcis peels as green corrosion inhibitors of mild steel in aggressive chloride media. J. Mol. Liq. 2019, 276, 347-361. [CrossRef] 
93. Saha, S.K.; Murmu, M.; Murmu, N.C.; Banerjee, P. Evaluating electronic structure of quinazolinone and pyrimidinone molecules for its corrosion inhibition effectiveness on target specific mild steel in the acidic medium: A combined DFT and MD simulation study. J. Mol. Liq. 2016, 224, 629-638. [CrossRef]

94. Kumar, D.; Jain, V.; Rai, B. Unravelling the mechanisms of corrosion inhibition of iron by henna extract: A density functional theory study. Corros. Sci. 2018, 142, 102-109. [CrossRef]

95. Srivastava, V.; Haque, J.; Verma, C.; Singh, P.; Lgaz, H.; Salghi, R.; Quraishi, M.A. Amino acid based imidazolium zwitterions as novel and green corrosion inhibitors for mild steel: Experimental, DFT and MD studies. J. Mol. Liq. 2017, 244, 340-352. [CrossRef]

96. Rodríguez-Gómez, F.J.; Valdelamar, M.P.; Vazquez, A.E.; Del Valle Perez, P.; Mata, R.; Miralrio, A.; Castro, M. Mycophenolic acid as a corrosion inhibitor of carbon steel in $3 \% \mathrm{wt}$. $\mathrm{NaCl}$ solution. An experimental and theoretical study. J. Mol. Struct. 2019, 1183, 168-181. [CrossRef]

97. Arshadi, M.R.; Lashgari, M.; Parsafar, G.A. Cluster approach to corrosion inhibition problems: Interaction studies. Mater. Chem. Phys. 2004, 86, 311-314. [CrossRef]

98. Garcia-Ochoa, E.; Guzmán-Jiménez, S.J.; Hernández, J.G.; Pandiyan, T.; Vásquez-Pérez, J.M.; Cruz-Borbolla, J. Benzimidazole ligands in the corrosion inhibition for carbon steel in acid medium: DFT study of its interaction on $\mathrm{Fe}_{30}$ surface. J. Mol. Struct. 2016, 1119, 314-324. [CrossRef]

99. Cruz-Borbolla, J.; Garcia-Ochoa, E.; Narayanan, J.; Maldonado-Rivas, P.; Pandiyan, T.; Vásquez-Pérez, J.M. Electrochemical and theoretical studies of the interactions of a pyridyl-based corrosion inhibitor with iron clusters $\left(\mathrm{Fe}_{15}, \mathrm{Fe}_{30}, \mathrm{Fe}_{45}\right.$, and $\left.\mathrm{Fe}_{60}\right)$. J. Mol. Model. 2017, 23, 342. [CrossRef] [PubMed]

100. Mousavi, M.; Mohammadalizadeh, M.; Khosravan, A. Theoretical investigation of corrosion inhibition effect of imidazole and its derivatives on mild steel using cluster model. Corros. Sci. 2011, 53, 3086-3091. [CrossRef]

101. Mousavi, M.; Safarizadeh, H.; Khosravan, A. A new cluster model based descriptor for structure-inhibition relationships: A study of the effects of benzimidazole, aniline and their derivatives on iron corrosion. Corros. Sci. 2012, 65, 249-258. [CrossRef]

102. Jamalizadeh, E.; Hosseini, S.M.A.; Jafari, A.H. Quantum chemical studies on corrosion inhibition of some lactones on mild steel in acid media. Corros. Sci. 2009, 51, 1428-1435. [CrossRef]

103. Mousavi, M.; Baghgoli, T. Application of interaction energy in quantitative structure-inhibition relationship study of some benzenethiol derivatives on copper corrosion. Corros. Sci. 2016, 105, 170-176. [CrossRef]

104. Aldana-González, J.; Espinoza-Vázquez, A.; Romero-Romo, M.; Uruchurtu-Chavarin, J.; Palomar-Pardavé, M. Electrochemical evaluation of cephalothin as corrosion inhibitor for API 5L X52 steel immersed in an acid medium. Arab. J. Chem. 2019, 12, 3244-3253. [CrossRef]

105. Saxena, A.; Sharma, V.; Thakur, K.K.; Bhardwaj, N. Electrochemical Studies and the Surface Examination of Low Carbon Steel by Applying the Extract of Citrus sinensis. J. Bio- Tribo-Corros. 2020, 6, 41. [CrossRef]

106. Abod, B.M.; Al-Alawy, R.M.; Khadom, A.A.; Kamar, F.H. Experimental and Theoretical Studies for Tobacco Leaf Extract as an Eco-friendly Inhibitor for Steel in Saline Water. J. Bio- Tribo-Corros. 2019, 5, 75. [CrossRef]

107. Abdulazeez, I.; Zeino, A.; Kee, C.W.; Al-Saadi, A.A.; Khaled, M.; Wong, M.W.; Al-Sunaidi, A.A. Mechanistic studies of the influence of halogen substituents on the corrosion inhibitive efficiency of selected imidazole molecules: A synergistic computational and experimental approach. Appl. Surf. Sci. 2019, 471, 494-505. [CrossRef]

108. Tourabi, M.; Nohair, K.; Traisnel, M.; Jama, C.; Bentiss, F. Electrochemical and XPS studies of the corrosion inhibition of carbon steel in hydrochloric acid pickling solutions by 3,5-bis(2-thienylmethyl)4-amino-1,2,4-triazole. Corros. Sci. 2013, 75, 123-133. [CrossRef]

109. Walczak, M.S.; Morales-Gil, P.; Lindsay, R. Determining Gibbs energies of adsorption from corrosion inhibition efficiencies: Is it a reliable approach? Corros. Sci. 2019, 155, 182-185. [CrossRef]

110. Khadom, A.A.; Abd, A.N.; Ahmed, N.A. Xanthium strumarium leaves extracts as a friendly corrosion inhibitor of low carbon steel in hydrochloric acid: Kinetics and mathematical studies. S. Afr. J. Chem. Eng. 2018, 25, 13-21. [CrossRef]

111. Hussin, M.H.; Jain Kassim, M.; Razali, N.N.; Dahon, N.H.; Nasshorudin, D. The effect of Tinospora crispa extracts as a natural mild steel corrosion inhibitor in $1 \mathrm{M} \mathrm{HCl}$ solution. Arab. J. Chem. 2016, 9, S616-S624. [CrossRef]

112. Li, D.; Zhang, P.; Guo, X.; Zhao, X.; Xu, Y. The inhibition of mild steel corrosion in $0.5 \mathrm{M} \mathrm{H}_{2} \mathrm{SO}_{4}$ solution by radish leaf extract. RSC Adv. 2019, 9, 40997-41009. [CrossRef] 
113. Ishak, A.; Adams, F.V.; Madu, J.O.; Joseph, I.V.; Olubambi, P.A. Corrosion Inhibition of Mild Steel in 1 M Hydrochloric Acid using Haematostaphis barteri Leaves Extract. Procedia Manuf. 2019, 35, 1279-1285. [CrossRef]

114. Benarioua, M.; Mihi, A.; Bouzeghaia, N.; Naoun, M. Mild steel corrosion inhibition by Parsley (Petroselium Sativum) extract in acidic media. Egypt. J. Pet. 2019, 28, 155-159. [CrossRef]

115. Afia, L.; Salghi, R.; Bammou, L.; Bazzi, E.L.; Hammouti, B.; Bazzi, L.; Bouyanzer, A. Anti-corrosive properties of Argan oil on $\mathrm{C}_{38}$ steel in molar $\mathrm{HCl}$ solution. J. Saudi Chem. Soc. 2014, 18, 19-25. [CrossRef]

116. Saeed, M.T.; Saleem, M.; Usmani, S.; Malik, I.A.; Al-Shammari, F.A.; Deen, K.M. Corrosion inhibition of mild steel in $1 \mathrm{M} \mathrm{HCl}$ by sweet melon peel extract. J. King Saud Univ. Sci. 2019, 31, 1344-1351. [CrossRef]

117. Raghavendra, N.; Ishwara Bhat, J. Inhibition of $\mathrm{Al}$ corrosion in $0.5 \mathrm{M} \mathrm{HCl}$ solution by Areca flower extract. J. King Saud Univ. Eng. Sci. 2019, 31, 202-208. [CrossRef]

118. Umoren, S.A.; Eduok, U.M.; Solomon, M.M.; Udoh, A.P. Corrosion inhibition by leaves and stem extracts of Sida acuta for mild steel in $1 \mathrm{M} \mathrm{H}_{2} \mathrm{SO}_{4}$ solutions investigated by chemical and spectroscopic techniques. Arab. J. Chem. 2016, 9, S209-S224. [CrossRef]

119. Bammou, L.; Belkhaouda, M.; Salghi, R.; Benali, O.; Zarrouk, A.; Zarrok, H.; Hammouti, B. Corrosion inhibition of steel in sulfuric acidic solution by the Chenopodium ambrosioides Extracts. J. Assoc. Arab Univ. Basic Appl. Sci. 2014, 16, 83-90. [CrossRef]

120. Alaneme, K.K.; Olusegun, S.J.; Adelowo, O.T. Corrosion inhibition and adsorption mechanism studies of Hunteria umbellata seed husk extracts on mild steel immersed in acidic solutions. Alex. Eng. J. 2016, 55, 673-681. [CrossRef]

121. Nwabanne, J.T.; Okafor, V.N. Adsorption and thermodynamics study of the inhibition of corrosion of mild steel in $\mathrm{H}_{2} \mathrm{SO}_{4}$ medium using Vernonia amygdalina. J. Miner. Mater. Charact. Eng. 2012, 11, 885.

122. Dagdag, O.; Safi, Z.; Hsissou, R.; Erramli, H.; El Bouchti, M.; Wazzan, N.; Guo, L.; Verma, C.; Ebenso, E.E.; El Harfi, A. Epoxy pre-polymers as new and effective materials for corrosion inhibition of carbon steel in acidic medium: Computational and experimental studies. Sci. Rep. 2019, 9, 11715. [CrossRef]

123. Alinnor, I. Corrosion Inhibition of Aluminium in Acidic Medium by Different Extracts of Ocimum gratissimum. Am. Chem. Sci. J. 2012, 2, 122-135. [CrossRef]

124. Alaneme, K.K.; Olusegun, S.J. Corrosion inhibition performance of lignin extract of sun flower (Tithonia diversifolia) on medium carbon low alloy steel immersed in $\mathrm{H}_{2} \mathrm{SO}_{4}$ solution. Leonardo J. Sci. 2012, 20, 59-70.

125. Ebenso, E.E.; Alemu, H.; Umoren, S.A.; Obot, I.B. Inhibition of mild steel corrosion in sulphuric acid using alizarin yellow GG dye and synergistic iodide additive. Int. J. Electrochem. Sci. 2008, 3, 1325-1339.

126. Chauhan, L.R.; Gunasekaran, G. Corrosion inhibition of mild steel by plant extract in dilute $\mathrm{HCl}$ medium. Corros. Sci. 2007, 49, 1143-1161. [CrossRef]

127. Dehghani, A.; Bahlakeh, G.; Ramezanzadeh, B. Green Eucalyptus leaf extract: A potent source of bio-active corrosion inhibitors for mild steel. Bioelectrochemistry 2019, 130, 107339. [CrossRef] [PubMed]

128. Alibakhshi, E.; Ramezanzadeh, M.; Haddadi, S.A.; Bahlakeh, G.; Ramezanzadeh, B.; Mahdavian, M. Persian Liquorice extract as a highly efficient sustainable corrosion inhibitor for mild steel in sodium chloride solution. J. Clean. Prod. 2019, 210, 660-672. [CrossRef]

129. Haldhar, R.; Prasad, D. Corrosion Resistance and Surface Protective Performance of Waste Material of Eucalyptus globulus for Low Carbon Steel. J. Bio- Tribo-Corros. 2020, 6, 48. [CrossRef]

130. Wang, Q.; Tan, B.; Bao, H.; Xie, Y.; Mou, Y.; Li, P.; Chen, D.; Shi, Y.; Li, X.; Yang, W. Evaluation of Ficus tikoua leaves extract as an eco-friendly corrosion inhibitor for carbon steel in $\mathrm{HCl}$ media. Bioelectrochemistry 2019, 128, 49-55. [CrossRef] [PubMed]

131. Saxena, A.; Prasad, D.; Haldhar, R.; Singh, G.; Kumar, A. Use of Saraca ashoka extract as green corrosion inhibitor for mild steel in $0.5 \mathrm{M} \mathrm{H}_{2} \mathrm{SO}_{4}$. J. Mol. Liq. 2018, 258, 89-97. [CrossRef]

132. Akbarzadeh, S.; Ramezanzadeh, M.; Ramezanzadeh, B.; Bahlakeh, G. A green assisted route for the fabrication of a high-efficiency self-healing anti-corrosion coating through graphene oxide nanoplatform reduction by Tamarindus indiaca extract. J. Hazard. Mater. 2020, 390, 122147. [CrossRef]

133. Deyab, M.A.; Guibal, E. Enhancement of corrosion resistance of the cooling systems in desalination plants by green inhibitor. Sci. Rep. 2020, 10, 4812. [CrossRef]

134. Ben Harb, M.; Abubshait, S.; Etteyeb, N.; Kamoun, M.; Dhouib, A. Olive leaf extract as a green corrosion inhibitor of reinforced concrete contaminated with seawater. Arab. J. Chem. 2020, 13, 4846-4856. [CrossRef] 
135. Faiz, M.; Zahari, A.; Awang, K.; Hussin, H. Corrosion inhibition on mild steel in $1 \mathrm{M} \mathrm{HCl}$ solution by Cryptocarya nigra extracts and three of its constituents (alkaloids). RSC Adv. 2020, 10, 6547-6562. [CrossRef]

136. Mobin, M.; Basik, M.; Aslam, J. Pineapple stem extract (Bromelain) as an environmental friendly novel corrosion inhibitor for low carbon steel in $1 \mathrm{M} \mathrm{HCl}$. Measurement 2019, 134, 595-605. [CrossRef]

137. Boudalia, M.; Fernández-Domene, R.M.; Tabyaoui, M.; Bellaouchou, A.; Guenbour, A.; García-Antón, J. Green approach to corrosion inhibition of stainless steel in phosphoric acid of Artemesia herba albamedium using plant extract. J. Mater. Res. Technol. 2019, 8, 5763-5773. [CrossRef]

138. Emori, W.; Zhang, R.-H.; Okafor, P.C.; Zheng, X.-W.; He, T.; Wei, K.; Lin, X.-Z.; Cheng, C.-R. Adsorption and corrosion inhibition performance of multi-phytoconstituents from Dioscorea septemloba on carbon steel in acidic media: Characterization, experimental and theoretical studies. Colloids Surf. Physicochem. Eng. Asp. 2020, 590, 124534. [CrossRef]

139. Akinbulumo, O.A.; Odejobi, O.J.; Odekanle, E.L. Thermodynamics and adsorption study of the corrosion inhibition of mild steel by Euphorbia heterophylla L. extract in $1.5 \mathrm{M} \mathrm{HCl}$. Results Mater. 2020, 5, 100074. [CrossRef]

140. Anyiam, C.K.; Ogbobe, O.; Oguzie, E.E.; Madufor, I.C.; Nwanonenyi, S.C.; Onuegbu, G.C.; Obasi, H.C.; Chidiebere, M.A. Corrosion inhibition of galvanized steel in hydrochloric acid medium by a physically modified starch. SN Appl. Sci. 2020, 2, 520. [CrossRef]

141. Haddadi, S.A.; Alibakhshi, E.; Bahlakeh, G.; Ramezanzadeh, B.; Mahdavian, M. A detailed atomic level computational and electrochemical exploration of the Juglans regia green fruit shell extract as a sustainable and highly efficient green corrosion inhibitor for mild steel in $3.5 \mathrm{wt} \% \mathrm{NaCl}$ solution. J. Mol. Liq. 2019, 284, 682-699. [CrossRef]

142. Ogunleye, O.O.; Arinkoola, A.O.; Eletta, O.A.; Agbede, O.O.; Osho, Y.A.; Morakinyo, A.F.; Hamed, J.O. Green corrosion inhibition and adsorption characteristics of Luffa cylindrica leaf extract on mild steel in hydrochloric acid environment. Heliyon 2020, 6, e03205. [CrossRef]

143. Wang, H.; Gao, M.; Guo, Y.; Yang, Y.; Hu, R. A natural extract of tobacco rob as scale and corrosion inhibitor in artificial seawater. Desalination 2016, 398, 198-207. [CrossRef]

144. Buyuksagis, A.; Dİlek, M. The Use of Papaver somniferum L. Plant Extract as Corrosion Inhibitor. Prot. Met. Phys. Chem. Surf. 2019, 55, 1182-1194. [CrossRef]

145. Ahanotu, C.C.; Onyeachu, I.B.; Solomon, M.M.; Chikwe, I.S.; Chikwe, O.B.; Eziukwu, C.A. Pterocarpus santalinoides leaves extract as a sustainable and potent inhibitor for low carbon steel in a simulated pickling medium. Sustain. Chem. Pharm. 2020, 15, 100196. [CrossRef]

146. Sanaei, Z.; Ramezanzadeh, M.; Bahlakeh, G.; Ramezanzadeh, B. Use of Rosa canina fruit extract as a green corrosion inhibitor for mild steel in $1 \mathrm{M} \mathrm{HCl}$ solution: A complementary experimental, molecular dynamics and quantum mechanics investigation. J. Ind. Eng. Chem. 2019, 69, 18-31. [CrossRef]

147. Akbarzadeh, S.; Ramezanzadeh, B.; Bahlakeh, G.; Ramezanzadeh, M. Molecular/electronic/atomic-level simulation and experimental exploration of the corrosion inhibiting molecules attraction at the steel/chloride-containing solution interface. J. Mol. Liq. 2019, 296, 111809. [CrossRef]

148. Divya, P.; Subhashini, S.; Prithiba, A.; Rajalakshmi, R. Tithonia diversifolia flower Extract as green Corrosion Inhibitor for Mild Steel in Acid Medium. Mater. Today Proc. 2019, 18, 1581-1591. [CrossRef]

149. Gadow, H.S.; Motawea, M.M. Investigation of the corrosion inhibition of carbon steel in hydrochloric acid solution by using ginger roots extract. RSC Adv. 2017, 7, 24576-24588. [CrossRef]

150. Dehghani, A.; Bahlakeh, G.; Ramezanzadeh, B.; Ramezanzadeh, M. Potential role of a novel green eco-friendly inhibitor in corrosion inhibition of mild steel in $\mathrm{HCl}$ solution: Detailed macro/micro-scale experimental and computational explorations. Constr. Build. Mater. 2020, 245, 118464. [CrossRef]

151. Bahlakeh, G.; Dehghani, A.; Ramezanzadeh, B.; Ramezanzadeh, M. Highly effective mild steel corrosion inhibition in $1 \mathrm{M} \mathrm{HCl}$ solution by novel green aqueous Mustard seed extract: Experimental, electronic-scale DFT and atomic-scale MC/MD explorations. J. Mol. Liq. 2019, 293, 111559. [CrossRef]

152. Anupama, K.K.; Ramya, K.; Shainy, K.M.; Joseph, A. Adsorption and electrochemical studies of Pimenta dioica leaf extracts as corrosion inhibitor for mild steel in hydrochloric acid. Mater. Chem. Phys. 2015, 167, $28-41$. [CrossRef]

153. Oguzie, E.E.; Enenebeaku, C.K.; Akalezi, C.O.; Okoro, S.C.; Ayuk, A.A.; Ejike, E.N. Adsorption and corrosion-inhibiting effect of Dacryodis edulis extract on low-carbon-steel corrosion in acidic media. J. Colloid Interface Sci. 2010, 349, 283-292. [CrossRef] 
154. Mourya, P.; Banerjee, S.; Singh, M.M. Corrosion inhibition of mild steel in acidic solution by Tagetes erecta (Marigold flower) extract as a green inhibitor. Corros. Sci. 2014, 85, 352-363. [CrossRef]

155. Bouknana, D.; Hammouti, B.; Messali, M.; Aouniti, A.; Sbaa, M. Olive pomace extract (OPE) as corrosion inhibitor for steel in $\mathrm{HCl}$ medium. Asian Pac. J. Trop. Dis. 2014, 4, S963-S974. [CrossRef]

156. Muthukrishnan, P.; Jeyaprabha, B.; Prakash, P. Adsorption and corrosion inhibiting behavior of Lannea coromandelica leaf extract on mild steel corrosion. Arab. J. Chem. 2017, 10, S2343-S2354. [CrossRef]

157. Hamdy, A.; El-Gendy, N.S. Thermodynamic, adsorption and electrochemical studies for corrosion inhibition of carbon steel by henna extract in acid medium. Egypt. J. Pet. 2013, 22, 17-25. [CrossRef]

158. Dehghani, A.; Bahlakeh, G.; Ramezanzadeh, B. A detailed electrochemical/theoretical exploration of the aqueous Chinese gooseberry fruit shell extract as a green and cheap corrosion inhibitor for mild steel in acidic solution. J. Mol. Liq. 2019, 282, 366-384. [CrossRef]

159. Gerengi, H.; Uygur, I.; Solomon, M.; Yildiz, M.; Goksu, H. Evaluation of the inhibitive effect of Diospyros kaki (Persimmon) leaves extract on St37 steel corrosion in acid medium. Sustain. Chem. Pharm. 2016, 4, 57-66. [CrossRef]

160. Muthukrishnan, P.; Prakash, P.; Jeyaprabha, B.; Shankar, K. Stigmasterol extracted from Ficus hispida leaves as a green inhibitor for the mild steel corrosion in $1 \mathrm{M} \mathrm{HCl}$ solution. Arab. J. Chem. 2019, 12, 3345-3356. [CrossRef]

161. Kumar, K.P.V.; Pillai, M.S.N.; Thusnavis, G.R. Seed Extract of Psidium guajava as Ecofriendly Corrosion Inhibitor for Carbon Steel in Hydrochloric Acid Medium. J. Mater. Sci. Technol. 2011, 27, 1143-1149. [CrossRef]

162. Alibakhshi, E.; Ramezanzadeh, M.; Bahlakeh, G.; Ramezanzadeh, B.; Mahdavian, M.; Motamedi, M. Glycyrrhiza glabra leaves extract as a green corrosion inhibitor for mild steel in $1 \mathrm{M}$ hydrochloric acid solution: Experimental, molecular dynamics, Monte Carlo and quantum mechanics study. J. Mol. Liq. 2018, 255, 185-198. [CrossRef]

163. Lukovits, I.; Kálmán, E.; Zucchi, F. Corrosion Inhibitors-Correlation between Electronic Structure and Efficiency. Corrosion 2001, 57, 3-8. [CrossRef]

164. Zhang, J.; Qiao, G.; Hu, S.; Yan, Y.; Ren, Z.; Yu, L. Theoretical evaluation of corrosion inhibition performance of imidazoline compounds with different hydrophilic groups. Corros. Sci. 2011, 53, 147-152. [CrossRef]

165. Khaled, K.F. Studies of iron corrosion inhibition using chemical, electrochemical and computer simulation techniques. Electrochim. Acta 2010, 55, 6523-6532. [CrossRef]

166. Musa, A.Y.; Jalgham, R.T.T.; Mohamad, A.B. Molecular dynamic and quantum chemical calculations for phthalazine derivatives as corrosion inhibitors of mild steel in $1 \mathrm{M} \mathrm{HCl}$. Corros. Sci. 2012, 56, 176-183. [CrossRef]

167. Al-Nami, S. Corrosion Inhibition Effect and Adsorption Activities of methanolic myrrh extract for Cu in $2 \mathrm{M}$ $\mathrm{HNO}_{3}$. Int. J. Electrochem. Sci. 2020, 1187-1205. [CrossRef]

168. Esquivel López, A.; Cuevas-Arteaga, C.; Valladares-Cisneros, M.G. Universidad Autónoma del Estado de Morelos Study of the corrosion inhibition of copper in synthetic seawater by Equisetum arvense as green corrosion inhibitor. Rev. Mex. Ing. Quim. 2019, 19, 603-616. [CrossRef]

169. Chung, I.-M.; Malathy, R.; Kim, S.-H.; Kalaiselvi, K.; Prabakaran, M.; Gopiraman, M. Ecofriendly green inhibitor from Hemerocallis fulva against aluminum corrosion in sulphuric acid medium. J. Adhes. Sci. Technol. 2020, 1-24. [CrossRef]

170. Sastri, V.S. Green Corrosion Inhibitors: Theory and Practice; John Wiley and Sons: Hoboken, NJ, USA, 2011; ISBN 1-118-01417-0.

171. Pedraza Basulto, G.K.; Carrillo, I.; Ortega, D.; Martinez, L.; Canto, J. Evaluation at Pipeline Corrosion at Oil Field. ECS Trans. 2015, 64, 103-110. [CrossRef]

(C) 2020 by the authors. Licensee MDPI, Basel, Switzerland. This article is an open access article distributed under the terms and conditions of the Creative Commons Attribution (CC BY) license (http://creativecommons.org/licenses/by/4.0/). 